\title{
Silver Nanoparticles as Chlorhexidine and Metronidazole Drug Delivery Platforms: Their Potential Use in Treating Periodontitis
}

\author{
Karol P Steckiewicz (1D) \\ Piotr Cieciórski $\mathbb{D}^{2}$ \\ Ewelina Barcińska' \\ Maciej Jaśkiewicz (iD) ${ }^{3}$ \\ Magdalena Narajczyk (iD) \\ Marta Bauer ${ }^{3}$ \\ Wojciech Kamysz (1D) ${ }^{3}$ \\ Elżbieta Megiel $^{2}$ \\ Iwona Inkielewicz- \\ Stepniak (D) 1 \\ 'Department of Pharmaceutical \\ Pathophysiology, Faculty of Pharmacy, \\ Medical University of Gdansk, Gdansk, \\ Poland; ${ }^{2}$ Faculty of Chemistry, University \\ of Warsaw, Warsaw, Poland; \\ ${ }^{3}$ Department of Inorganic Chemistry, \\ Faculty of Pharmacy, Medical University \\ of Gdansk, Gdansk, Poland; ${ }^{4}$ Laboratory \\ of Electron Microscopy, Faculty of \\ Biology, University of Gdansk, Gdansk, \\ Poland
}

\begin{abstract}
Purpose: Periodontal disease (PD), defined as oral inflammation caused by dental plaque, is an emerging problem. PD may lead to tooth loss, and treatment options are limited. In this study, we designed, synthesized, and characterized silver nanoparticles (AgNPs) conjugated with chlorhexidine (AgNPs-CHL) or metronidazole (AgNPs-PEG-MET) to determine whether they can be used to treat PDs.
\end{abstract}

Materials and Methods: AgNPs were synthesized and characterized by transmission electron microscopy, UV-vis spectrometry, thermogravimetric analyses, and dynamic light scattering. We determined the safety and the antimicrobial and anti-inflammatory properties of synthesized AgNPs in an in vitro model of periodontitis. Antimicrobial properties were determined by measuring the minimum inhibitory concentration (MIC) and minimum biofilm eradication concentration (MBEC) on reference strains of bacteria and fungi. Human gingival fibroblast (HGF-1), murine macrophage (RAW264.7) and human foetal osteoblast (hFOB1.19) cells were used in the study. Lipopolysaccharide (LPS) was used to induce inflammation. Cytokine levels were measured using an enzyme-linked immunosorbent assay; metalloproteinase expression was measured using Western blotting.

Results: The synthesized AgNPs were spherical and narrow-dispersed with an average diameter of $13.4 \mathrm{~nm} \pm 3.0 \mathrm{~nm}$ in the case of AgNPs-CHL and $3.72 \mathrm{~nm} \pm 0.72 \mathrm{~nm}$ in the case of AgNPs-PEGMET. Both types of AgNPs were active against bacteria and fungi. AgNPs-CHL proved to be a more potent antimicrobial agent, although they were more cytotoxic than AgNPs-PEG-MET; however, both demonstrated beneficial properties in nontoxic concentrations. AgNPs-CHL and AgNPs-PEG-MET decreased the production of proinflammatory cytokines IL-1 $\beta$, IL-6, IL-8 and TNF $\alpha$. Both agents also decreased the levels of metalloproteinases MMP3 and MMP8, which may indicate that they will inhibit tissue degradation.

Conclusion: AgNPs-CHL and AgNPs-PEG-MET may be possible therapeutic options for $\mathrm{PD}$, as they have antibacterial and anti-inflammatory properties. However, to fully understand the potential of AgNPs, our in vitro findings must be evaluated in an in vivo model.

Keywords: drug delivery platforms, gingival fibroblast, macrophages, osteoblasts, periodontal disease, periodontitis

\section{Introduction}

Periodontal disease (PD) are an emerging clinical and epidemiological problem, the incidence of which is rising. ${ }^{1} \mathrm{PD}$ is divided into two categories: gingivitis and periodontitis. Gingivitis is defined as inflammation of the oral cavity caused by dental plaque produced by oral microflora. Periodontitis is a more severe disease which destroys the
Correspondence: Iwona InkielewiczStepniak

Tel +4858349 I516

Fax +48 $58349 \quad 1517$

Email iinkiel@gumed.edu.pl 


\section{Graphical Abstract}

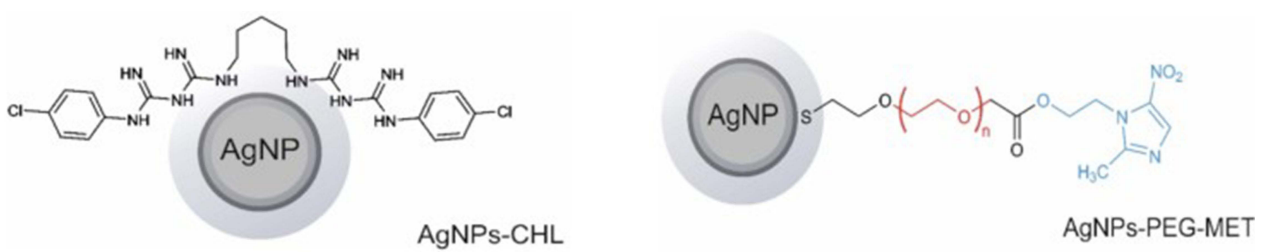

silver nanoparticles conjugated with chlorhexidine or metronidazole

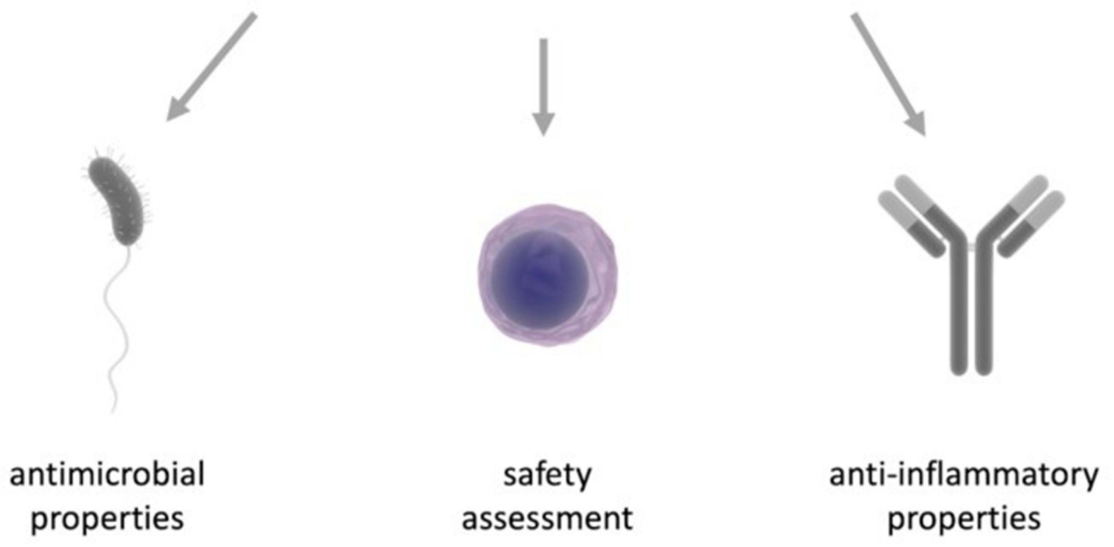

structure of the teeth, such as ligaments, bones, and soft tissues, and can cause tooth loss. ${ }^{2}$ Oral microbiota seems to play a crucial role in PD pathophysiology. The bacteria associated with PD are predominantly Gram-negative anaerobic bacteria (ie Porphyromonas spp., Treponema spp., Tannerella spp. and Aggregatibacter spp.). ${ }^{3}$ However, the initiation and further progression of PD is strictly associated with biofilm formation and imbalances between microbiota and immune response. Furthermore, evidence on the role of these bacteria in PD development is still growing. For example, Streptococcus mutans are frequently isolated from patients with severe PD. ${ }^{4}$ A high prevalence of Staphylococcus epidermidis in periodontal pockets and subgingival sites in PD patients has also been noted, while the presence of Staphylococcus aureus is considered critical for the exacerbation of the disease. ${ }^{5,6}$ On the other hand, biofilmassociated Acinetobacter spp. are associated with suppuration and the advance of PD into a chronic state. ${ }^{7,8}$ Fungi such as Candida albicans are also indicated as critical for PD persistence and progression, although its role has not yet been established. ${ }^{9}$ Contemporary dentistry has yet to find an effective method of resolving inflammation caused by oral infections, possibly because the mechanism of the disease is not yet fully understood. As the role of the formation of bacterial plaque in PD is well described, the mechanical removal of plaque and antiseptics are often used to manage these diseases. First, exfoliative and subgingival stone remedies are used. In more advanced cases, surgical procedures using materials that regenerate the tissues surrounding the tooth are necessary. Finally, special restorations are conducted to stabilize the teeth. ${ }^{10}$

In most cases, pharmacotherapy with bacteriostatic and bactericidal agents (parahydroxybenzoate, chlorhexidine, hyaluronic acid), antifungal agents (nystatin, fluconazole) and antibiotics (metronidazole clindamycin, amoxicillin) are also necessary. ${ }^{11-15}$ Bacteria eradication is often unsuccessful due to biofilm formation with a complex structure, which is poorly penetrated by drugs. Bacteria in biofilm are 100-1000 more resistant to treatment than planktonic ones. $^{16}$ The Federal Drug Administration (FDA) has approved only a few new antimicrobial agents in recent decades. ${ }^{17}$ Treating PD is a daunting challenge, and novel therapies are needed.

More uses for nanotechnology are being discovered every year, and it is being applied in many scientific fields, including medicine. Due to miniaturization, nanoparticles 
(NPs), defined as particles sized 1-100 nm, have different properties than their macro equivalent, such as a large surface-to-volume ratio, the ability to easily penetrate biological and structural barriers, etc. ${ }^{13}$ AgNPs have beneficial properties which may be used in dentistry and are often studied in that regard, ${ }^{12,18}$ primarily due to their antimicrobial efficacy, even against multidrug-resistant strains. ${ }^{19}$ Importantly, AgNPs are also effective against pathogens in biofilm. ${ }^{20}$ Craciunescu et al recently reported that AgNPs biosynthesized in collagen gel demonstrate antimicrobial activity against pathogens related to $\mathrm{PD}$ in non-toxic concentrations. ${ }^{21}$ In addition to their antimicrobial activity, AgNPs may have anti-inflammatory properties, which are especially beneficial in treating PD. ${ }^{19,22-24}$ Reports also suggest that AgNPs have antitumor properties against oral cancer cells in in vitro models, ${ }^{19}$ and they have been successfully used as drug delivery platforms. $^{25,26}$

Novel therapies using AgNPs and their conjugates with drugs can provide an excellent solution to PD treatment challenges. This work reports on the results of the synthesis of conjugates of AgNPs with two drugs: chlorhexidine and metronidazole. The chlorhexidine molecules in the obtained conjugates are directly connected to the silver surface (AgNPs-CHL), whereas the metronidazole molecules are attached to the silver surface via a polyethylene glycol (PEG) linker (AgNPs-PEG-MET). We examined the cytotoxicity, antimicrobial and anti-inflammatory properties of these conjugates in PD in an in vitro model.

Chlorhexidine is an antibacterial agent commonly used in dentistry due to 'its ability to disrupt bacterial cell walls in both gram-positive and gram-negative bacterial strains. $^{27}$ Metronidazole, on the other hand, is effective against protozoa and anaerobic bacteria. When internalized by a pathogen, metronidazole molecules create free radicals that can destroy the DNA of microorganisms. ${ }^{28}$

Recently published reports show that combining AgNPs with chlorhexidine and metronidazole produces excellent bacteriostatic and bactericidal effects. ${ }^{29}$ A synergic effect was observed when AgNPs were combined with chlorhexidine to treat an infected wound. ${ }^{30}$ However, to date, there has been no study of conjugates built of chlorhexidine/metronidazole attached to the surface of AgNPs. Rather than simply combining the drugs with AgNPs, conjugating them allows medicine to be delivered to the proper cells together at the same rate and enables bioactive components to be released gradually.
In this work, we synthesized and examined antimicrobial and anti-inflammatory properties of AgNPs conjugated with chlorhexidine or metronidazole to demonstrate that they can be used to treat PD. We evaluated their biological properties in periodontitis in an in vitro model.

\section{Materials and Methods Materials}

All compounds used in our studies had a purity of $>95 \%$, as determined by HPLC analyses. Chlorhexidine ( $\geq 99.5 \%)$, silver nitrate (ACS reagent, $\geq 99 \%$ ), sodium borohydride $(\geq$ 98\%), metronidazole (pharmaceutical secondary standard; $\geq 98 \%$ ), $\quad$ EDC $\quad$ (N-(3-Dimethylaminopropyl)-N'ethylcarbodiimide hydrochloride), HS-PEG-COOH poly (ethylene glycol) 2-mercaptoethyl ether acetic acid (average $M_{n}=1000 \mathrm{Da}$ ) and all solvents were purchased from Sigma-Aldrich (Germany). Milli-Q ultrapure water (resistivity: $18.2 \mathrm{M} \Omega \mathrm{cm}^{-1}$, Millipore-Merk) was used in all experiments. Dialysis cellulose membranes (Nadir, Bionovo) with a molecular weight cut-off (MWCO) of 10,000 Da were used to purify the synthesized NPs.

Six strains of microorganisms were used in the study. Acinetobacter lwoffii PCM 2235 was acquired from the Polish Collection of Microorganisms (Polish Academy of Sciences, Wroclaw), while Candida albicans ATCC 10231, Staphylococcus epidermidis ATCC 14990, S. epidermidis ATCC 2532, Stenotrophomonas maltophilia ATCC 12716 and Streptococcus mutans ATCC 29176 were obtained from the American Type Culture Collection (ATCC). The ATCC provided all the cell lines used in this study. Human gingival fibroblast (HGF-1), human foetal osteoblast (hFOB1.19) and murine macrophage (RAW264.7) cells were used in the study.

\section{Synthesis of Silver Nanoparticles Coated with Chlorhexidine}

Eighty milligrams $(79 \mu \mathrm{mol})$ of chlorhexidine were placed in a round-bottom flask and $40 \mathrm{~mL}$ of ultra-pure water was added. The flask was immersed in a cooling ice-water bath on a magnetic stirrer and intensively stirred for $30 \mathrm{~min}-$ utes. Afterwards, $78 \mu \mathrm{L}$ of an aqueous solution of $\mathrm{AgNO}_{3}$ (1M) was added and the solution was stirred for $15 \mathrm{~min}$ utes. A solution of $\mathrm{NaBH}_{4}$ in water $(16 \mathrm{mg}$ in $10 \mathrm{~mL})$, previously cooled in a refrigerator $\left(4^{\circ} \mathrm{C}\right)$, was subsequently added to the flask one drop at a time while the mixture was vigorously stirred. As the reducing agent was added, the originally colourless mixture gradually became yellow, then light brown and finally dark brown. Once all the 
$\mathrm{NaBH}_{4}$ had been added, the mixture was stirred at a slower rate for the next 2 hours. The prepared NPs were purified of inorganic compounds (derived from the oxidation of $\mathrm{NaBH}_{4}$ ) and non-attached chlorhexidine by dialysis (using ultrapure water, $1 \mathrm{~h}$, MWCO $10 \mathrm{kDa}$ ). The yield of the reaction calculated based on the ICP MS analysis was $68 \%$.

\section{Synthesis of Conjugates of Silver Nanoparticles with Metronidazole}

The synthesis was performed in two steps: 1) coupling metronidazole with HS-PEG-COOH via ester bonds; and 2) synthesising AgNPs using the compounds prepared in the first step as ligands and $\mathrm{NaBH}_{4}$ as a reducing agent. The carboxyl groups in PEG molecules were activated in the esterification process by EDC molecules to improve performance. $^{31}$

Eighty milligrams $(80 \mu \mathrm{mol})$ of HS-PEG-COOH, $27 \mathrm{mg}$ $(160 \mu \mathrm{mol})$ of metronidazole and $34 \mathrm{mg}(176 \mu \mathrm{mol})$ of EDC were placed in a round-bottom flask and dissolved in $10 \mathrm{~mL}$ of ultra-pure water. The flask was placed on a magnetic stirrer and stirred for 48 hours. Next, the flask was immersed in a cooling ice-water bath on a magnetic stirrer, $40 \mu \mathrm{L}$ of an aqueous solution of $\mathrm{AgNO}_{3}(1 \mathrm{M})$ was added, and the mixture was stirred for 15 minutes. A solution of $\mathrm{NaBH}_{4}$ in water ( $9 \mathrm{mg}$ in $6 \mathrm{~mL}$ ), previously cooled in a refrigerator, was subsequently added to the flask one drop at a time while the mixture was vigorously stirred. As the reducing agent was added, the originally colourless mixture gradually became yellow, then light brown and finally a transparent dark brown. Once all the $\mathrm{NaBH}_{4}$ had been added, the mixture was stirred at a slower rate for the next 24 hours. Finally, the NPs were purified of inorganic compounds (derived from the oxidation of $\mathrm{NaBH}_{4}$ ) and non-attached ligands by dialysis (using ultrapure water, $24 \mathrm{~h}, \mathrm{MWCO}$ $10 \mathrm{kDa}$ ). The final solution was dark brown, and the yield of the reaction, calculated based on the ICP MS analysis, was $27 \%$.

\section{Characterisation of the Nanoparticles UV-Vis Spectrophotometry}

UV-Vis spectra were recorded using a Cary 50 Conc UV/ Vis spectrophotometer (Varian). The spectra were recorded in aqueous solutions. ${ }^{32}$

\section{Dynamic Light Scattering}

Dynamic Light Scattering (DLS) measurements were performed with a Zetasizer Nano series apparatus (Malvern) equipped with a He-Ne laser $(4 \mathrm{~mW})$ at $632.8 \mathrm{~nm}$ and a thermostatted cell holder. The hydrodynamic diameters of the particles present in the aqueous solutions were measured at $25^{\circ} \mathrm{C}$. The solutions were equilibrated for 10 minutes before measurement. ${ }^{33}$

\section{Thermogravimetric Analyses (TGA)}

Thermogravimetric (TG) measurements were performed using a TA Instruments DSC Q20 apparatus (TA instruments) with thermobalance (precision $\pm 0.4 \%$; minimal mass $0.02 \mathrm{mg}$ ) in an $\mathrm{N}_{2}$ atmosphere with a scanning rate of $10 \mathrm{~K} \mathrm{~min}^{-1}$. 32

\section{Laser Ablation Inductively Coupled Plasma Mass Spectrometry}

The concentrations of silver in the aqueous solutions of the synthesized AgNPs were determined using a highresolution laser ablation inductively coupled plasma mass spectrometer (LA-ICP-MS; Atom ES-HR-ICP-MS-Nu Instruments). The spectrometer is connected to the Teledyne CETAC Aridus3 Desolvating Nebulizer System, a specialized liquid sample introduction accessory for ICP-MS. ${ }^{33}$

\section{Antimicrobial Activity Microorganisms}

All strains were stored at $-80^{\circ} \mathrm{C}$ in ROTI Store cryo vials. Before the tests the strains were transferred to fresh Mueller-Hinton broth (Biocorp) for bacteria or RPMI1640 (Sigma-Aldrich) for fungi and incubated for 24 hours at $37^{\circ} \mathrm{C}$ while being shaken at $120 \mathrm{rpm}$. The cultures were then seeded on Mueller-Hinton agar (BioMaxima) or Sabouraud dextrose agar (BioMaxima) plates and incubated as described. These agar cultures were used for further microbiological assays. Cell densities for all assays were adjusted spectrophotometrically (Multiskan GO Microplate Spectrophotometer, Thermo Fisher Scientific) at 600 and $530 \mathrm{~nm}$ for bacteria and fungi, respectively.

\section{Activity Against Planktonic Cultures}

Minimum inhibitory concentrations (MICs) were determined using the broth microdilution method on 96-well polystyrene plates, according to Clinical and Laboratory Standards Institute recommendations. ${ }^{34,35}$ To do this, initial inoculums of bacteria $\left(5 \times 10^{5} \mathrm{CFU} / \mathrm{mL}\right)$ in MuellerHinton Broth and fungi $\left(2 \times 10^{3} \mathrm{CFU} / \mathrm{mL}\right)$ in RPMI-1640 with $2 \% \mathrm{D}$-glucose were exposed to the ranging concentration of tested compounds $(0.03125-32 \mu \mathrm{g} / \mathrm{mL})$ and incubated at $37^{\circ} \mathrm{C}$ for 18 and 24 hours, respectively. The MIC was taken as the lowest concentration at which 
noticeable growth of microorganisms was inhibited. All experiments were conducted in triplicate. ${ }^{36}$

\section{Activity Against Biofilm}

Minimum biofilm eradication concentrations (MBECs) were assessed on 96-well polystyrene flat-bottom plates according to the protocol described above. ${ }^{37,38}$ For this purpose, after 24 hours of growth, the cultures of microorganisms were diluted to obtain a final density of $5.0 \times$ $10^{5} \mathrm{CFU} / \mathrm{mL}$ and $2.0 \times 10^{5} \mathrm{CFU} / \mathrm{mL}$ of bacteria and fungi, respectively. Microorganisms were diluted in MuellerHinton broth or RPMI-1640 with 2\% D-glucose (bacteria and fungi, respectively). Briefly, $100 \mu \mathrm{L}$ of cell suspension was added to the test plates and incubated for 24 hours at $37^{\circ} \mathrm{C}$. The wells were then rinsed three times with PBS (phosphate-buffered saline) ( $\mathrm{pH}$ 7.4) to remove nonadherent cells. Subsequently, $100 \mu \mathrm{L}$ of the test compounds in a concentration range of $0.03125-32 \mu \mathrm{g} / \mathrm{mL}$ were added to each well. After 24 hours of incubation at $37^{\circ} \mathrm{C}, 20 \mu \mathrm{L}$ of a cell viability reagent was added (resazurin, $4 \mathrm{~g} / \mathrm{L}$; Sigma Aldrich). The MBEC was read after 1 hour of incubation with shaking at $120 \mathrm{rpm}$. The determined values were recorded as the lowest concentration at which the reduction of resazurin (from blue to pink) was $\leq 10 \pm 0.5 \%$ compared to the positive $(100 \%)$ and negative $(0 \%)$ controls. The reduction was monitored by measuring absorbance at $570 \mathrm{~nm}$ (reduced) and $600 \mathrm{~nm}$ (oxidized) using a microplate spectrophotometer (Multiskan GO Microplate Spectrophotometer, Thermo Fisher Scientific). All experiments were conducted in triplicate. ${ }^{36}$

\section{Transmission Electron Microscopy}

To characterise the NPs, transmission electron microscopy (TEM) analyses were performed using a JEM 1400 JEOL Co. microscope (JEOL) at $120 \mathrm{kV}$ acceleration voltage. The aqueous solution of the sample (with a concentration $1 \mathrm{mg} / \mathrm{mL}$ ) was cast onto a carbon-coated copper microgrid (200 mesh) and air-dried for 24 hours. ${ }^{32}$

A different TEM protocol was used to investigate NP internalization and ultrastructural changes in hFOB1.19 cells, S. mutans and S. maltophilia. The hFOB1.19 cells were plated in a 6-well plate. After 24 hours, the cells were incubated with AgNPs-CHL $(1 \mu \mathrm{g} / \mathrm{mL})$ or AgNPsPEG-MET $(1 \mu \mathrm{g} / \mathrm{mL})$. S. maltophilia and S. mutans were grown overnight $\left(37^{\circ} \mathrm{C}\right.$, shaken). The bacterial cells were centrifuged at $3500 \mathrm{rpm}$ for 7 minutes and resuspended in a fresh Mueller-Hinton medium to obtain a dense cell suspension of $5 \times 10^{5} \mathrm{CFU} / \mathrm{mL}$. The cells were then exposed to NPs at MIC concentrations and incubated for 18 hours at $37^{\circ} \mathrm{C}$. After treatment, bacterial cells were centrifuged at $3500 \mathrm{rpm}$ for 10 minutes and washed twice with PBS. The hFOB1.19 cells, S. maltophilia and S. mutans were fixed in $2.5 \%$ electron microscopy grade glutaraldehyde (Polysciences) in 0.1 M PBS (pH 7.4), post-fixed in $1 \%$ osmium tetroxide (Polysciences), dehydrated in a graded series of ethanol $(30 \%-100 \%)$ and embedded in Epon (Sigma). Ultrathin $(65 \mathrm{~nm})$ sections were cut using a Leica UC7 Ultramicrotome, stained with UranyLess (Delta Microscopies) and Reynold's lead citrate (Delta Microscopies), and examined on a Tecnai G2 Spirit BioTWIN TEM at $120 \mathrm{kV}^{37}$

\section{Cell Culture}

HGF-1 (ATCC CRL-2014) and RAW264.7 (ATCC TIB71) cells were cultured in Dulbecco's Modified Eagle's Medium. The hFOB1.19 cells (ATCC CRL-11372) were cultured in a 1:1 mixture of Ham's F12 Medium Dulbecco's Modified Eagle's Medium and $2.5 \mathrm{mM}$ L-glutamine. Media for all cell lines were supplemented with $10 \%$ foetal bovine serum and $1 \%$ antibiotics (penicillin/streptomycin). We followed the provider's recommendations for all cell cultures. The cells were kept at $37^{\circ} \mathrm{C}$ in a humidified atmosphere of $5 \% \mathrm{CO}_{2}$. The cells were cultured under sterile conditions and maintained in a $75 \mathrm{~cm}^{2}$ tissue culture flask. The medium was replaced every 48 hours. When confluent, the HGF-1 and hFOB1.19 cells were detached using trypsin-EDTA solution and cultured in a new flask. The RAW264.7 cells were detached by scraping them. ${ }^{39}$

\section{MTT Assay}

The cells were plated in a 96-well plate, incubated overnight and treated with AgNPs-CHL or AgNPs-PEG-MET for 24 hours. The NPs solutions were prepared ex tempore in FBS-free media. Sonication was performed to ensure that the NPs were distributed equally. Control cells were treated with media but without FBS. AgNPs-CHL were tested in concentration ranges of $0.2-3 \mu \mathrm{g} / \mathrm{mL}$ and AgNPsPEG-MET were tested in concentration ranges of $0.2-10$ $\mu \mathrm{g} / \mathrm{m}$. After 24 hours the media was supplemented with water-soluble tetrazolium salt to a final concentration $0.5 \mathrm{mg} / \mathrm{mL}$ and incubated for 2 hours. After incubation, the media was removed and crystals were dissolved in DMSO. Absorbance was measured with a Synergy H1 microplate reader (Biotek), using $540 \mathrm{~nm}$ and $630 \mathrm{~nm}$ as references. The variability of the cells is presented as 
percentage of control. Absorbances were corrected with blank NPs. The MTT assay protocol used is described above. $^{39}$

\section{Measurement of Cytokine Levels}

The IL-1 $\beta$, Il-6, IL-8, and TNF $\alpha$ levels were measured in cell culture medium or cell lysate using commercially available enzyme-linked immunosorbent assays (DuoSet ELISA, R\&D Systems). Cells were plated in a 6-well plate, incubated overnight and then treated with AgNPsCHL or AgNPs-PEG-MET for 24 hours. The NPs solutions were prepared ex tempore in FBS-free media. Sonication was performed to ensure equal distribution of NPs. The control cells were treated with FBS-free media. Two hours later, the cells were stimulated with $1 \mu \mathrm{g} / \mathrm{mL}$ of LPS (Sigma-Aldrich). AgNPs-CHL was used in concentrations of $0.5,1.5$ and $3 \mu \mathrm{g} / \mathrm{mL}$, while AgNPs-PEG-MET was used in concentrations of 1,5 and $10 \mu \mathrm{g} / \mathrm{mL}$. After 24 hours the media were collected, aliquoted and stored at $-80^{\circ} \mathrm{C}$. The cells were lysed in a lysis buffer with protease inhibitors. The cell lysate was aliquoted and stored at $-80^{\circ} \mathrm{C}$. All tests were performed according to the manufacturers' protocols. Samples, standard curves, and negative controls were measured using a Synergy H1 microplate reader (Biotek) at $450 \mathrm{~nm}$ with a wavelength correction of $540 \mathrm{~nm}$. The stimulation protocol for RAW264.7 was based on Moro et $\mathrm{al}^{40}$ and the use of DuoSet ELISA was previously established by Kim and Lee. $^{6}$

\section{Detection of Reactive Oxygen Species}

The cells were plated in a 6-well plate, incubated overnight and treated with AgNPs-CHL or AgNPs-PEG-MET for 24 hours. NPs solutions were prepared ex tempore in FBS-free media. Sonication was performed to ensure equal distribution of NPs. The control cells were treated with FBS-free media. Two hours later, the cells were stimulated with $1 \mu \mathrm{g} / \mathrm{mL}$ of LPS (Sigma-Aldrich). AgNPs-CHL were used in concentrations of $0.5,1.5$ and $3 \mu \mathrm{g} / \mathrm{mL}$, while AgNPs-PEG-MET were used in concentrations of 1,5 and $10 \mu \mathrm{g} / \mathrm{mL}$. After 24 hours, the media were supplemented with $10 \mu \mathrm{M}$ 2,7-dichlorofluorescein diacetate (DCF-DA, Sigma Aldrich). After 30 minutes the cells were detached and samples were prepared. The fluorescence of the oxidized DCF was measured using flow cytometry (excitation wavelength: $480 \mathrm{~nm}$; emission wavelength: $525 \mathrm{~nm}$ ). Data were expressed as percentage of untreated cells using a BD FACS Calibur cytometer with dedicated software (Cell Quest Pro). ${ }^{36}$

\section{Western Blotting}

The levels of metalloproteinases MMP3, MMP8 and MMP9 were measured using Western blotting. Cells were plated in $100 \mathrm{~mm}$ Petri dishes, incubated overnight and treated with AgNPs-CHL or AgNPs-PEG-MET for 24 hours. NP solutions were prepared ex tempore in FBS-free media. Sonication was performed to ensure equal distribution of NPs. The control cells were treated with FBS-free media. Two hours after NPs treatment, the cells were stimulated with $10 \mu \mathrm{g} / \mathrm{mL}$ of LPS (Sigma-Aldrich). AgNPs-CHL was used in concentrations $0.5,1.5$ and 3 $\mu \mathrm{g} / \mathrm{mL}$, while AgNPs-PEG-MET was used in concentrations 1,5 and $10 \mu \mathrm{g} / \mathrm{mL}$. After 24 hours the medium was removed, the cells were washed, detached and lysed and the protein levels were measured using the Bradford method. Once the samples were prepared, they were subjected to electrophoresis; the proteins were then transferred to nitrocellulose membranes (Protran, Schleicher and Schuell BioScience) and detected using antibodies (Abcam). $\beta$-Actin (Abcam) was used as the loading control. Immunoactive proteins were detected using an enhanced chemiluminescence Western blotting detection kit (Amersham Biosciences). Protein levels were quantified using densitometry software (ImageLab, Bio-Rad). The method was previously established and described by our team, ${ }^{39}$ and our stimulation protocol was based on those of Feng et al, Sun et al, De Colli et al, Li et al and Yu et al. ${ }^{41-45}$

\section{Statistical Analysis}

Each experiment was replicated independently three times. Data are presented as mean \pm standard deviation. Statistical analyses were performed using Prism 9 software (GraphPad), one-way analysis of variance (ANOVA) and either Tukey's or Dunnett's post hoc test. The $\mathrm{IC}_{50}$ was calculated by analysing a nonlinear regression log (inhibitor) vs normalized response. ${ }^{39}$

\section{Results}

In this study, we synthesized and characterized novel conjugates of AgNPs with chlorhexidine (AgNPs-CHL) and metronidazole (AgNPs-PEG-MET). We evaluated them as potential therapeutic options for periodontitis by determining their antimicrobial and anti-inflammatory potential. We 
also assessed the safety of the potential application of the synthesized AgNPs conjugates as a novel nanotherapy.

AgNPs-CHL was tested as an aqueous solution with the starting concentration of silver determined from an ICP-MS analysis at $114 \mathrm{ppm}$ containing $0.3 \mathrm{mg} / \mathrm{mL}$ of the conjugate. The UV-vis spectra of the synthesized AgNPs-CHL were recorded after the addition of $\mathrm{NaBH} 4$ and after dialysis (Figure 1).

AgNPs-PEG-MET was employed as an aqueous solution with the starting concentration of silver determined from an ICP-MS analysis at $71 \mathrm{ppm}$ containing $0.2 \mathrm{mg} / \mathrm{mL}$ of the conjugate, $15 \%$ of which consisted of metronidazole (determined from TGA).

Thin Layer Chromatography (TLC) ${ }^{46}$ was used to verify that the nanoparticle solution was free of impurities.

\section{Characterisation of the Nanoparticles UV-Vis Spectroscopy and TEM}

The UV-Vis spectra recorded for the aqueous solutions of AgNPs-CHL and AgNPs-PEG-MET are presented in Figure 1.

In the spectrum of AgNPs-CHL, which was recorded after adding a reducing agent to the reaction system, the intensive band of surface plasmon resonance (SPR) at 409 $\mathrm{nm}$ was symmetrical and narrow. However, after excess chlorhexidine had been removed (via dialysis), the observed band widened, indicating that some of the NPs increased in size during this process. This phenomenon occurred because chlorhexidine is only weakly connected with the surface, so the combination of NPs could run

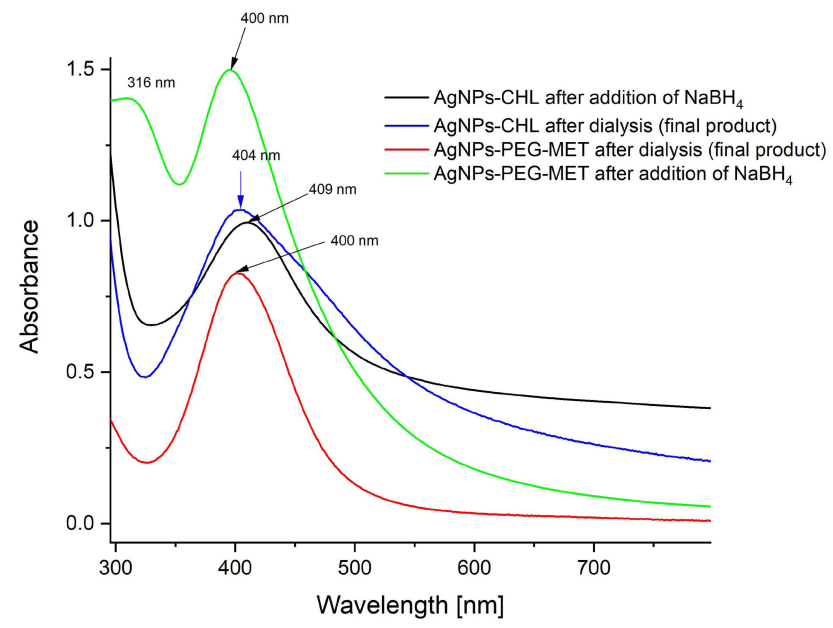

Figure I UV-VIS spectra of AgNPs-CHL and AgNPs-PEG-MET recorded in water solutions. during dialysis. Thus, this process cannot be carried out for a long time (aggregation was observed after $5 \mathrm{~h}$ ).

The UV-VIS spectrum of AgNPs-PEG-MET (Figure 1) indicates that their metallic cores are spherical, small and equal in size. It was reported that for spherical AgNPs, only one band of SPR is observed, and if it is narrow, the polydispersity is low; furthermore, if the maximum SPR band is close to $400 \mathrm{~nm}$, the diameter of the NPs is in the range of a few nanometres. ${ }^{47}$

In the spectrum of AgNPs-PEG-MET recorded before excess metronidazole was removed via dialysis, a characteristic band for this compound was visible at $316 \mathrm{~nm}$. This band disappeared after dialysis, as the amount of metronidazole was too small to be visible.

The SPR band in the UV-VIS spectrum recorded for AgNPs-PEG-MET solution was located at a shorter wavelength than that for AgNPs-CHL, so the first-mentioned NPs should be smaller.

The TEM results were consistent with those obtained from UV-VIS spectroscopy. Micrographs of the synthesized NPs and the histograms drawn based on them are presented in Figure 2. For the AgNPs-CHL sample, the average diameter of the NPs was $d=13 \pm 3 \mathrm{~nm}$. It is most likely that the tiny fraction of NPs with a larger diameter $(16 \mathrm{~nm}<\mathrm{d}<25 \mathrm{~nm})$ visible in Figure 2A were responsible for the slight broadening of the SPR band (Figure 1). Thus, the widening of the SPR band results from the size dispersity of NPs visible in the microscopic images.

The average diameter of the NPs in the AgNPs-PEGMET sample was significantly lower $(d=3.7 \pm 0.7 \mathrm{~nm})$. The differences between the size of NPs follow their other connection of ligand with the silver surface. Chlorhexidine connects directly to the surface of the silver via the relatively weak interaction between nitrogen atoms and metal atoms. In contrast, metronidazole is connected through a PEG linker attached to the nanoparticle via the significantly stronger thiolate Ag-S bonds. These semi-covalent bonds offer good protection for silver and gold NPs against aggregation. ${ }^{48}$ Therefore, during the synthesis of AgNPs-PEG-MET, the ligands containing metronidazole bind to the metal surface fast and stably, preventing further nanoparticle growth. It is worth mentioning that in the case of thiolate-stabilized AgNPs, bioactivity may be limited due to the metallic core of the densely covered nanoparticle. However, our results and those of other studies indicate that such AgNPs can exhibit high antimicrobial activity. $^{32,49-51}$ 
A

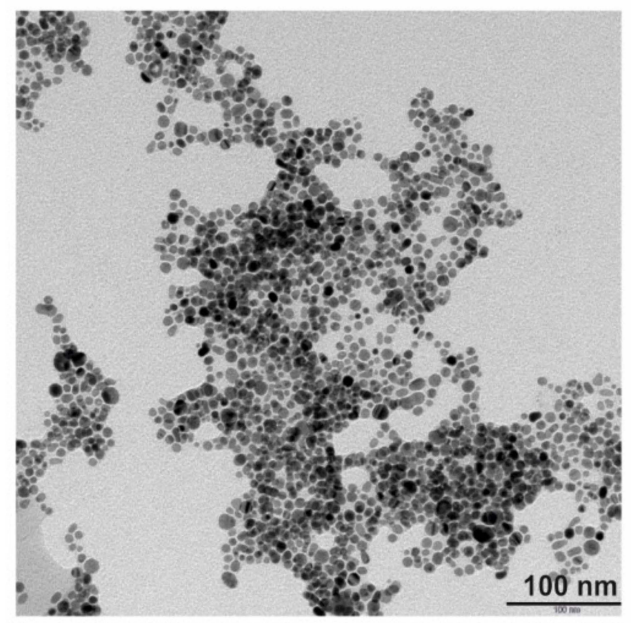

C

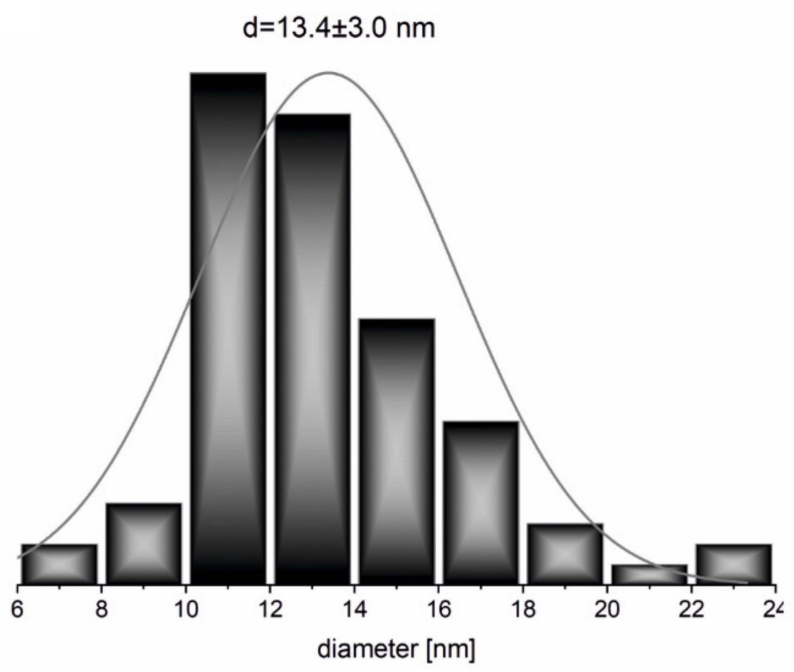

B
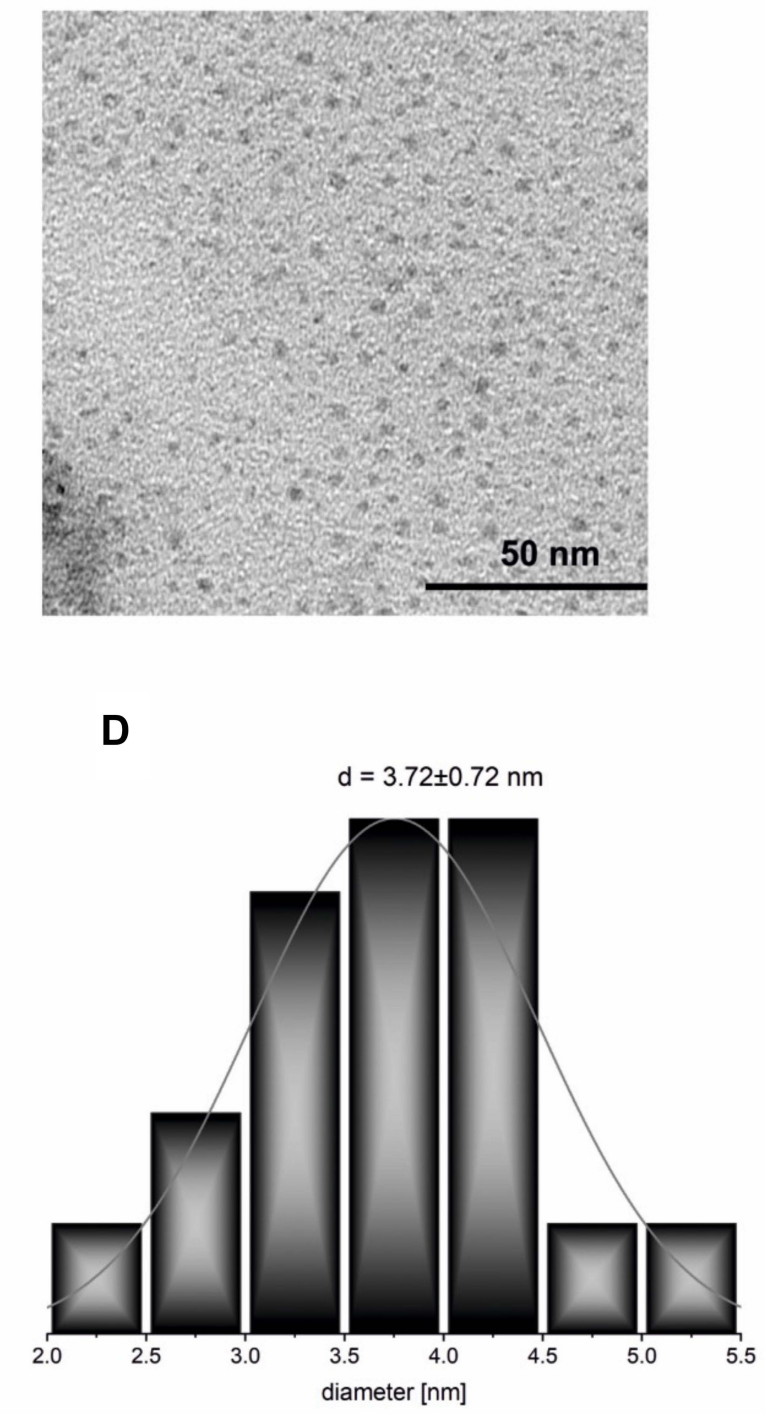

Figure 2 TEM micrographs of the synthesized NPs: (A) AgNPs-CHL; (B) AgNPs-PEG-MET; (C) AgNPs-CHL; (D) AgNPs-PEG-MET. The histograms were prepared based on these images.

\section{DLS Analyses}

DLS measurements allowed us to analyse the size and dispersity of the synthesized NPs, including the stabilization layer attached to the metal surface. The size dispersity curves (calculated by the number of NPs) and the average hydrodynamic diameters determined are shown in Figure 3. For AgNPs-PEG-MET, the average size of the NPs was $6.39 \mathrm{~nm}$ and the dispersity was narrow; for the AgNPs-CHL sample, the main peak was narrow, with an average of $27.93 \mathrm{~nm}$, but a small fraction of larger NPs was visible. UV-VIS spectra and TEM analyses also revealed the presence of a small fraction of larger NPs in this material (see above). It is worth adding that DLS shows that the stabilizing layer was very thick for both types of synthesized NPs, which offers better protection against aggregation. Considering the average diameter obtained using the DLS measurements (which determined the whole nanoparticle size) and that using the TEM measurements (in which only the metal core was visible), we calculated the thickness of the stabilizing layer for both synthesized NPs: AgNPs-PEG-MET was $2.67 \pm 0.55 \mathrm{~nm}$, while AgNPs-CHL was $14.53 \pm 1.53 \mathrm{~nm}$. 


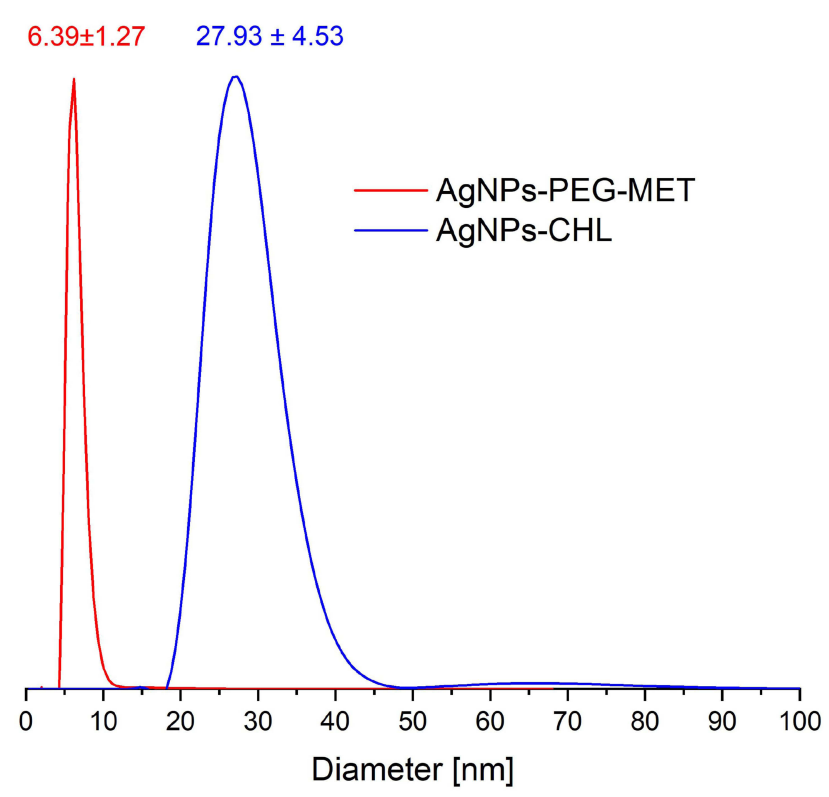

Figure 3 The number averaged hydrodynamic diameter distribution of the synthesized NPs obtained from DLS measurements.

\section{TGA Analyses}

The content of the medicines attached to the surface of the NPs was determined using TGA, and the results of these analyses were used to evaluate the stability of the synthesized nanomaterials. The TGA curves for the synthesized AgNPs-CHL and the drug used for their preparation are presented in Figure 4.

Thermal decomposition of chlorhexidine (CHL) was completed below $700^{\circ} \mathrm{C}$ and no residual mass was observed. The process comprises three main steps, with

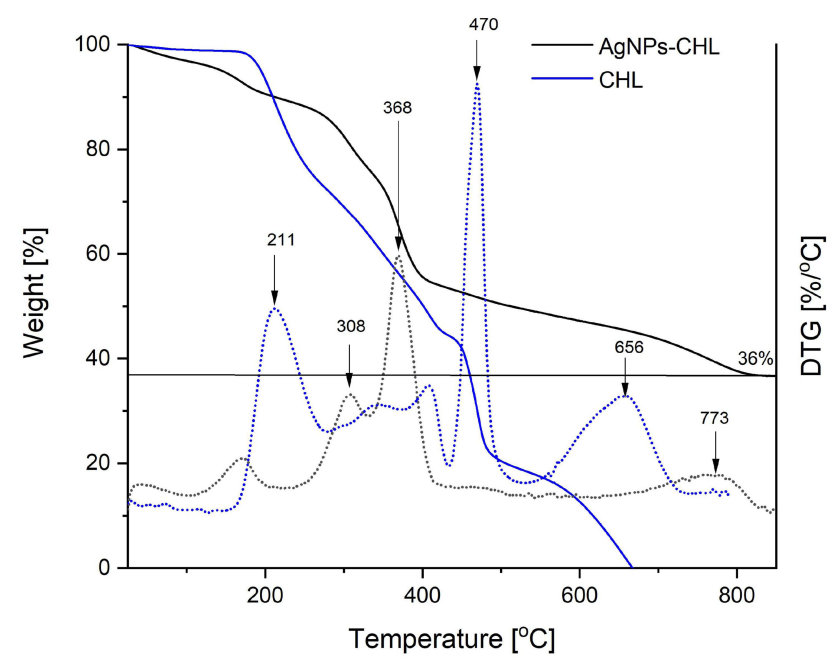

Figure 4 TGA curves recorded during the heating $\mathrm{AgNPs}-\mathrm{CHL}$ and $\mathrm{CHL}$ not attached on the silver surface under nitrogen atmosphere (solid lines) and their derivatives with temperature (dotted lines with the same colours). maximums of $211^{\circ} \mathrm{C}, 470{ }^{\circ} \mathrm{C}$ and $656^{\circ} \mathrm{C}$. The final mass obtained after heating the AgNPs-CHL to $800^{\circ} \mathrm{C}$ corresponded to the silver content in this material $(36 \%$ of the initial mass). Based on this value, the concentration of chlorhexidine in a solution can be easily calculated if its silver content is known (for example, from ICP MS), as the AgNPs-CHL consists of only these two components. The thermal stability of fabricated AgNPs-CHL is higher than that of pure chlorhexidine, and the main steps of its decomposition must be carried out at higher temperatures (Figure 4).

The TGA curves recorded for metronidazole, the AgNPs coated with this drug (AgNPs-PEG-MET) and the PEG derivatives used to link the silver and the drug are shown in Figure 5.

The composition of AgNPs-PEG-MET was determined using the TGA measurements. As shown in Figure 5, metronidazole decomposes completely below $300^{\circ} \mathrm{C}$, while PEG begins decomposing above $300^{\circ} \mathrm{C}$. The percentage of mass, $85 \%$, corresponds to the part of the sample after decomposition of metronidazole, meaning that its content is $15 \% \mathrm{w} / \mathrm{w}$. The residue above $800^{\circ} \mathrm{C}$ corresponds to the silver content in the sample (36\%). In the sample, the PEG connecting the medicine to silver comprised $49 \%$.

The thermal decomposition of the metronidazole attached to AgNPs occurs at a lower temperature than the non-attached (maximum decomposition occurs at $180^{\circ} \mathrm{C}$ in the case of AgNPs-PEG-MET and at $254^{\circ} \mathrm{C}$ for

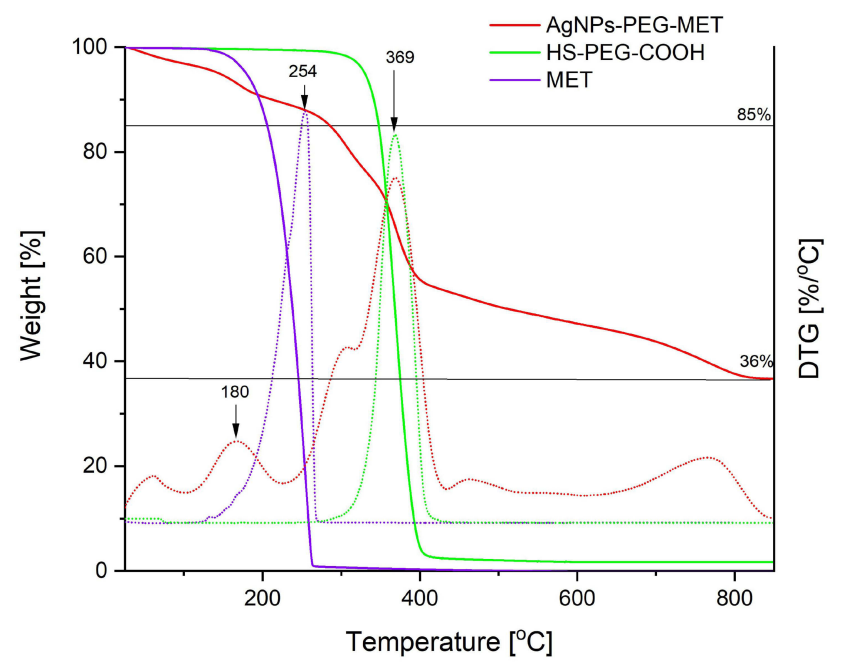

Figure 5 TGA curves recorded during the heating of AgNPs-PEG-MET. MET is metronidazole not attached to the silver surface, and PEG is a derivative used to link the silver and the drug. The measurements were taken under a nitrogen atmosphere (solid lines); derivatives of the curves with temperature are represented as dotted lines with the same colours. 
pure metronidazole). Decomposition probably requires less energy when these molecules are combined with PEG molecules via ester bonds. Differences are also visible in the decomposition of connected and free PEG: that of the PEG attached to the NPs requires several stages and ends at $800^{\circ} \mathrm{C}$ (Figure 5).

\section{Antimicrobial Activity}

Antimicrobial activity was evaluated using 5 reference strains of bacteria: 3 gram-positive strains ( $S$. maltophilia, S. mutans, and 2 strains of $S$. epidermidis); 1 gram-negative strain (A. lwoffii); and 1 reference strain of fungi (C. albicans). The strains of microorganisms were chosen based on human oral microflora composition.

Both AgNPs-CHL and AgNPs-PEG-MET exhibited high antimicrobial activity against all the strains included in this study. The highest activity was noticed for AgNPs-CHL and $S$. epidermidis, for which growth inhibition (Table 1) and biofilm eradication (Table 2 ) occurred below the concentration used in the assays $(\leq 0.03125 \mu \mathrm{g} / \mathrm{mL})$. Generally, AgNPs-CHL was characterized by the highest activity. For other Gram-positive bacteria, MIC values were also below the concentration range; however, the MBEC values were 4 times $(0.125 \mu \mathrm{g} / \mathrm{mL})$. In the case of $A$. lwoffii and $C$. albicans, growth was inhibited at 0.125 and $0.25 \mu \mathrm{g} / \mathrm{mL}$, respectively, and MBEC values were 8 times higher. The AgNPs-PEG-
MET inhibited the growth of all tested strains; however, contrary to AgNPs-CHL, it was more active against the Gram-negative strain and fungi. It also failed to eradicate the biofilm of $S$. epidermidis strains at the range of concentrations used in the experiments $(>32 \mu \mathrm{g} / \mathrm{mL})$. The MBEC values for $S$. maltophilia and $S$. mutans were also relatively high, at 16 and $32 \mu \mathrm{g} / \mathrm{mL}$, respectively. We observed a synergistic effect of drugs and NPs. AgNPs-CHL and AgNPs-PEG-MET demonstrated better antimicrobial activity than drugs alone in all cases. The antimicrobial activity of AgNPs-PEG-MET was particularly strong, as metronidazole inhibited the growth of only $A$. lwoffii, while AgNPs-PEGMET inhibited the growth of all tested bacteria other than $S$. epidermidis. Our TEM measurements did not reveal ultrastructural changes caused by NPs in bacterial cells, but we observed that AgNPs-CHL can be found in S. mutans and S. maltophilia. Interestingly, AgNPs-PEG-MET were found to be localized around the bacterial cell wall (Figure 6).

\section{Cytocompatibility}

To ensure that the agents were safe to use, we determined the impact of NPs on the viability of human gingival fibroblasts, human foetal osteoblasts and murine macrophage cell lines using MTT assay, which measures the $\mathrm{NAD}(\mathrm{P}) \mathrm{H}$-dependent oxidoreductase activity in mitochondria.

Table I Minimum Inhibitory Concentrations $(\mu \mathrm{g} / \mathrm{mL})$ Against Tested Strains

\begin{tabular}{|l|c|c|c|c|c|c|}
\hline & $\begin{array}{c}\text { A. Iwoffii } \\
\text { PCM 2235 }\end{array}$ & $\begin{array}{c}\text { C. albicans } \\
\text { ATCC 1023 I }\end{array}$ & $\begin{array}{c}\text { S. epidermidis } \\
\text { ATCC 14990 }\end{array}$ & $\begin{array}{c}\text { S. epidermidis } \\
\text { ATCC 2532 }\end{array}$ & $\begin{array}{c}\text { S. maltophilia } \\
\text { ATCC I27I6 }\end{array}$ & $\begin{array}{c}\text { S. mutans } \\
\text { ATCC 29I76 }\end{array}$ \\
\hline AgNPs-CHL & 0.125 & 0.25 & $\leq 0.03125$ & $\leq 0.03125$ & $\leq 0.03125$ & $\leq 0.03125$ \\
\hline AgNP-PEG-MET & 0.5 & 0.25 & 2 & 16 & 8 & 8 \\
\hline Chlorhexidine & 0.125 & 2 & $\leq 0.03125$ & 0.25 & 0.125 & 0.125 \\
\hline Metronidazole & 0.125 & $>32$ & $>32$ & $>32$ & $>32$ & $>32$ \\
\hline
\end{tabular}

Table 2 Minimum Biofilm Eradication Concentrations $(\mu \mathrm{g} / \mathrm{mL})$ Against Tested Strains

\begin{tabular}{|l|c|c|c|c|c|c|}
\hline & $\begin{array}{c}\text { A. Iwoffii } \\
\text { PCM 2235 }\end{array}$ & $\begin{array}{c}\text { C. albicans } \\
\text { ATCC 1023 I }\end{array}$ & $\begin{array}{c}\text { S. epidermidis } \\
\text { ATCC 14990 }\end{array}$ & $\begin{array}{c}\text { S. epidermidis } \\
\text { ATCC 2532 }\end{array}$ & $\begin{array}{c}\text { S. maltophilia } \\
\text { ATCC I27 I6 }\end{array}$ & $\begin{array}{c}\text { S. mutans } \\
\text { ATCC 29I76 }\end{array}$ \\
\hline AgNPs-CHL & I & 4 & $\leq 0.03125$ & 0.125 & 0.125 & 0.125 \\
\hline AgNP-PEG-MET & 1 & 4 & $>32$ & $>32$ & 16 & 32 \\
\hline Chlorhexidine & 16 & 8 & 0.5 & 1 & 0.125 & I \\
\hline Metronidazole & 1 & $>32$ & $>32$ & $>32$ & 32 \\
\hline
\end{tabular}



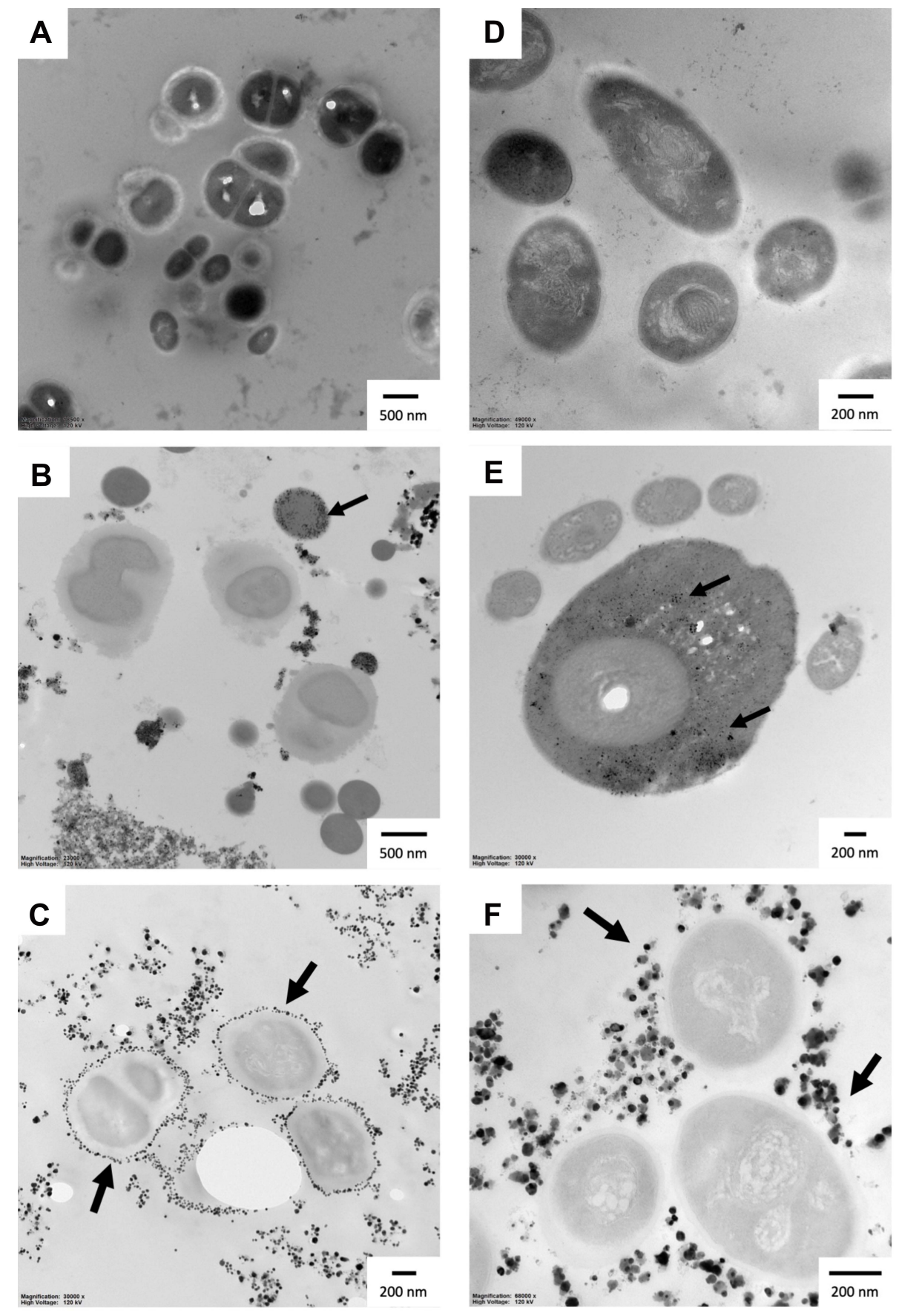

Figure 6 Ultrastructure of S. maltophilia and S. mutans after treatment with AgNPs for 24 hours: (A) S. maltophilia control; (B) S. maltophilia treated with AgNPs-CHL; (C) S. maltophilia treated with AgNPs-PEG-MET; (D) S. mutans control; (E) S. mutans treated with AgNPs-CHL; (F) S. mutans treated with AgNPs-PEG-MET. The scale bar is present on the left side of each picture. Arrows indicate NPs.

AgNPs-CHL, at a concentration range of $0-0.5 \mu \mathrm{g} / \mathrm{mL}$, did not impact the viability of the hFOB1.19, HGF1 and RAW264.7 cells. AgNPs-PEG-MET at a concentration range of $0-10 \mu \mathrm{g} / \mathrm{mL}$ did not decrease the viability of HGF-1, hFOB1.19 or RAW264.7. The cytotoxicity of the tested NPs was type- and concentration-dependent. AgNPs-PEG-MET were more biocompatible than AgNPs-
CHL. The $\mathrm{IC}_{50}$ values for both types of NPs are presented in Table 3, and the results are represented graphically in Supplementary Figure 1.

To further investigate the safety of AgNPs-CHL and AgNPs-PEG-MET, we calculated the selectivity index (SI). The higher a compound's SI value, the safer it is. Mean selectivity was calculated as mean $\mathrm{IC}_{50} / \mathrm{MIC}$ and 
Table 3 Half Maximal Inhibitory Concentration (IC50) for AgNPs-CHL and AgNPs-PEG-MET

\begin{tabular}{|l|c|c|c|}
\hline NPs Type & hFOBI.19 & HGF-I & RAW264.7 \\
\hline AgNPs-CHL & $2.332 \mu \mathrm{g} / \mathrm{mL}$ & $2.246 \mu \mathrm{g} / \mathrm{mL}$ & $8.425 \mu \mathrm{g} / \mathrm{mL}$ \\
\hline AgNPs-PEG-MET & $>10 \mu \mathrm{g} / \mathrm{mL}$ & $>10 \mu \mathrm{g} / \mathrm{mL}$ & $>10 \mu \mathrm{g} / \mathrm{mL}$ \\
\hline
\end{tabular}

mean $\mathrm{IC}_{50}$ for HGF-1 cells was calculated to $2.246(\mu \mathrm{g} /$ $\mathrm{mL}$ ) for AgNPs-CHL. Due to the lack of cytotoxicity for AgNPs-PEG-MET, we used $\mathrm{IC}_{50}$ higher than $10 \mu \mathrm{g} / \mathrm{mL}$ in the calculations. We observed high SI values for tested NPs, even above 71 for AgNPs-CHL and above 40 for AgNPs-PEG-MET. Our results were similar when we used the mean of $\mathrm{IC}_{50}$ for $\mathrm{hFOB} 1.19$ cells in our calculations. The SI values we obtained were high: above 109 for AgNPs-CHL and above 40 for AgNPs-PEG-MET. The exact SI values are presented in Table 4. TEM analysis also revealed that both types of NPs were present in hFOB1.19 cells (Figure 7). We observed that AgNPs were found in different cellular compartments. However, neither AgNPs-CHL nor AgNPs-PEG-MET caused major changes in the cells' ultrastructure. AgNPs-CHL was localized in the cytosol (Figure 7C and D), while AgNPs-PEGMET was found in the autophagic vacuoles (Figure 7E and F). Our NPs did not affect the ultrastructure of the mitochondria or the nucleus.

\section{Anti-Inflammatory Properties}

To assess the anti-inflammatory properties of NP drugs we examined their impact on cytokine production in LPSstimulated murine macrophages. After stimulation with LPS, we observed increased levels of IL-1 $\beta$, Il-6 and TNF $\alpha$ secreted by RAW264.7 cells to the medium. LPS stimulation did not increase the expression of IL-8. AgNPs-CHL in concentrations of 1.5 and $3 \mu \mathrm{g} / \mathrm{mL}$ significantly decreased the levels of IL-1 $\beta$, Il- 6 and TNF $\alpha$. Interestingly, $3 \mu \mathrm{g} / \mathrm{mL}$ of AgNPs-CHL decreased the $\mathrm{TNF} \alpha$ concentration below the levels produced by unstimulated control. AgNPs-PEG-MET at a concentration of
$10 \mu \mathrm{g} / \mathrm{mL}$ significantly decreased the levels of IL- $1 \beta$ and TNF $\alpha$ produced by stimulated RAW264.7 cells (Figure 8).

AgNPs-CHL and AgNPs-PEG-MET also decreased the intracellular levels of cytokines in stimulated RAW264.7 cells. AgNPs-CHL in concentrations of $0.5-3 \mu \mathrm{g} / \mathrm{mL}$ decreased levels of IL-1 $\beta$ and IL-8 in RAW264.7 lysate. A similar effect was observed for IL-6, but in concentrations of $1.5-3 \mu \mathrm{g} / \mathrm{mL}$ AgNPs-CHL. AgNPs-CHL did not impact the intracellular production of TNF $\alpha$. AgNPs-PEGMET decreased the production of IL-6 only (Figure 9).

We also assessed the impact of NP drugs on the intracellular levels of selected cytokines in LPS-stimulated HGF-1 cell lysates. However, neither AgNPs-CHL nor AgNPs-MET-PEG impacted intracellular IL-1 $\beta$, Il-6, IL-8 or TNF $\alpha$ levels (Supplementary Figure 2).

To further examine the anti-inflammatory properties of synthesized NPs, we determined their influence on ROS production using LPS-stimulated murine macrophages (RAW264.7). As intracellular production of ROS increases when macrophages are stimulated to produce an inflammatory response, ${ }^{52}$ we hypothesized that decreased production of ROS in LPS-stimulated macrophages may be one of the mechanisms of AgNPs-CHL's and AgNPs-PEG -MET's anti-inflammatory properties. After stimulation with LPS, we observed a statistically significant increase in ROS production in the RAW264.7 cells. Treatment with only the highest concentration of AgNPs-CHL $(3 \mu \mathrm{g} / \mathrm{mL})$ increased ROS production in LPS-stimulated RAW264.7 cells. AgNPs-PEG-MET did not impact ROS production in LPS stimulated RAW264.7 cells (Figure 10). This indicates that our NPs did not exert anti-inflammatory properties on ROS production.

\section{Impact on Metalloproteinase Expression}

The destruction of tissues is important in the pathophysiology of periodontitis. Metalloproteinases are important proteins involved in this process, so we assessed the effect of AgNPs-CHL and AgNPs-PEG-MET on the expression of these enzymes. LPS stimulation increased the intracellular

Table 4 Mean SI - Selectivity index (Mean IC50/MIC) for AgNPs-CHL and AgNPs-PEG-MET. The Mean IC50 Value for HGF-I Cells (Table 3) and MIC Values (Table I) Were Used in These Calculations. Values Were Rounded to the Nearest Decimal

\begin{tabular}{|l|c|c|c|c|c|c|}
\hline NPs Type & $\begin{array}{c}\text { SI A. Iwoffii } \\
\text { PCM 2235 }\end{array}$ & $\begin{array}{c}\text { SI C. albicans } \\
\text { ATCC 1023I }\end{array}$ & $\begin{array}{c}\text { SI S. epidermidis } \\
\text { ATCC I4990 }\end{array}$ & $\begin{array}{c}\text { SI S. epidermidis } \\
\text { ATCC 2532 }\end{array}$ & $\begin{array}{c}\text { SI S. maltophilia } \\
\text { ATCC I27I6 }\end{array}$ & $\begin{array}{c}\text { SI S. mutans } \\
\text { ATCC 29 I76 }\end{array}$ \\
\hline AgNPs-CHL & 17,97 & 8.98 & $>7 I, 87$ & $>71,87$ & $>71,87$ & $>7 I, 87$ \\
\hline AgNPs-PEG-MET & $>20$ & $>40$ & $>5$ & $>0.625$ & $>1,25$ & $>1,25$ \\
\hline
\end{tabular}



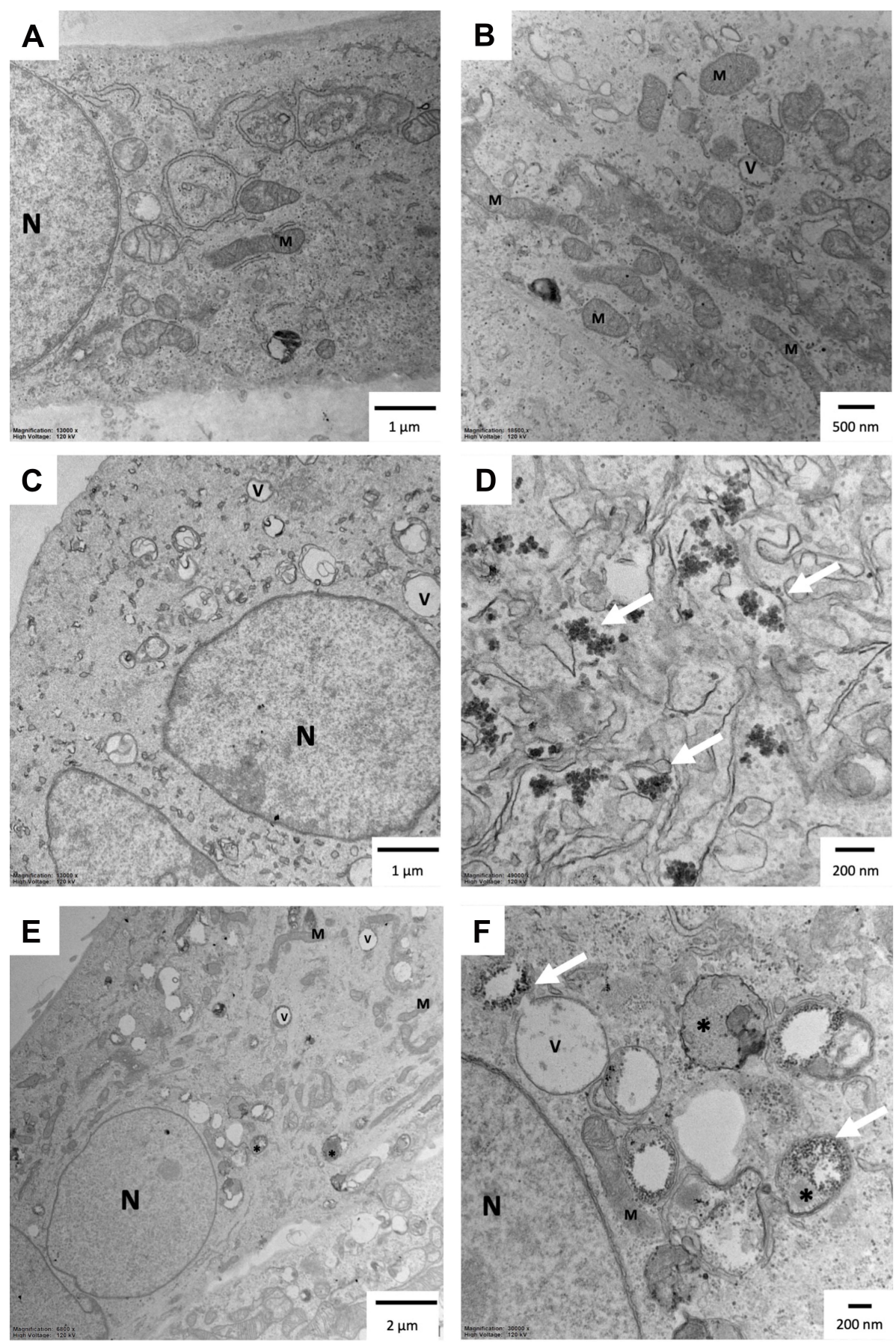

Figure 7 Ultrastructure of the hFOBI. 19 cells after 24 hours of incubation with AgNPs: (A and $\mathbf{B})$ control cells; (C and $\mathbf{D})$ cells treated with I $\mu g / \mathrm{mL}$ AgNPs-CHL; (E and F) cells treated with I $\mu \mathrm{g} / \mathrm{mL}$ AgNPs-PEG-MET. Arrows indicate NPs. *Autophagic vacuoles; $\mathrm{V}$-vacuoles; $\mathrm{N}$ - nucleus; $\mathrm{M}$ - mitochondria. The scale bar is present on the left side of each picture.

production of MMP3, MMP8 and MMP9 in hFOB1.19 cells. AgNPs-CHL at a concentration of $3 \mu \mathrm{g} / \mathrm{mL}$ and AgNPs-PEG-MET at a concentration of $10 \mu \mathrm{g} / \mathrm{mL}$ decreased the production of MMP3 and MMP8 (Figure 11).
LPS stimulation did not significantly affect metalloproteinase production in the HGF-1 cells. However, treatment with AgNPs-PEG-MET at a concentration of $10 \mu \mathrm{g} / \mathrm{mL}$ decreased MMP3 levels in the stimulated HGF-1 cells (Supplementary Figure 3). 

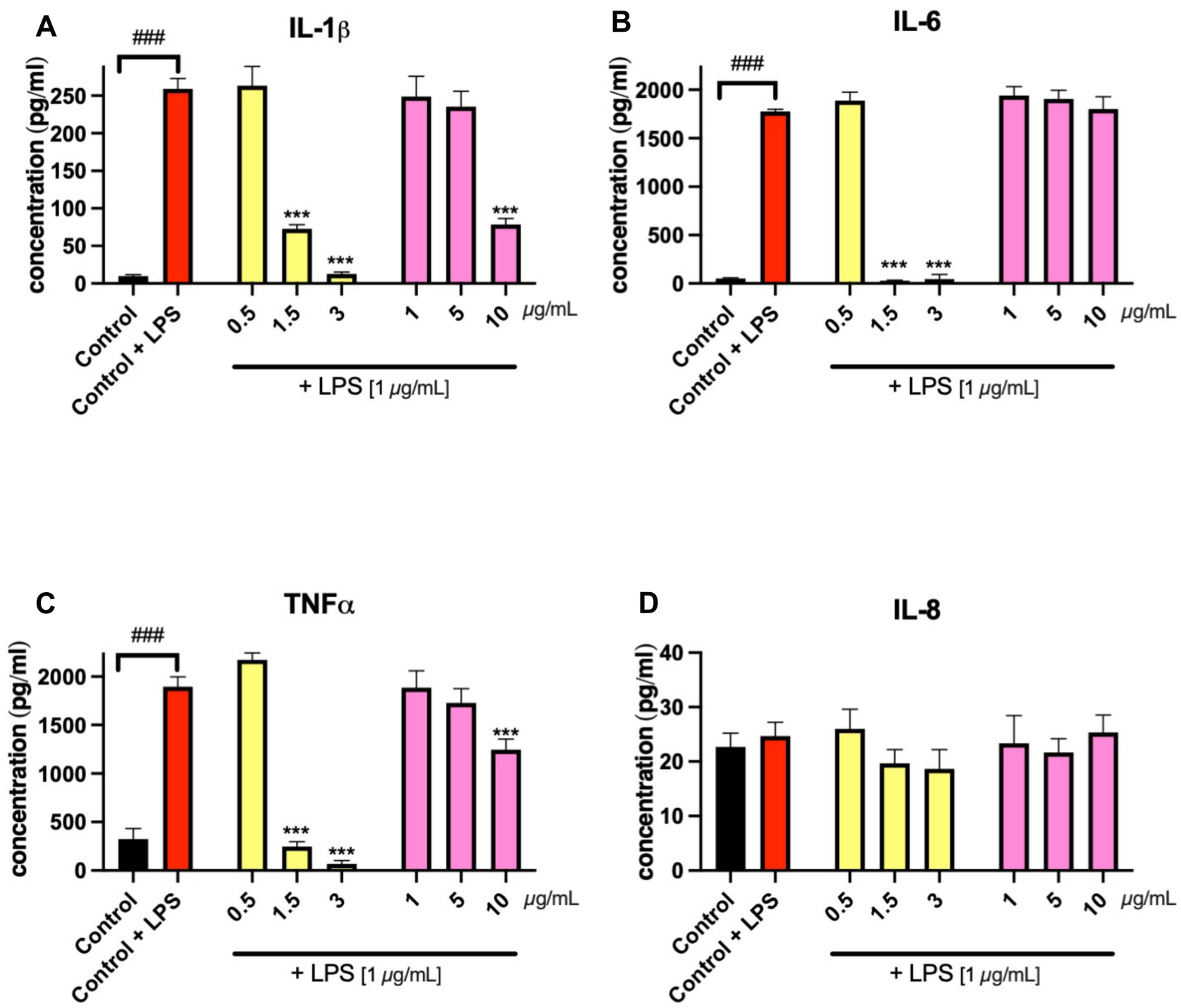
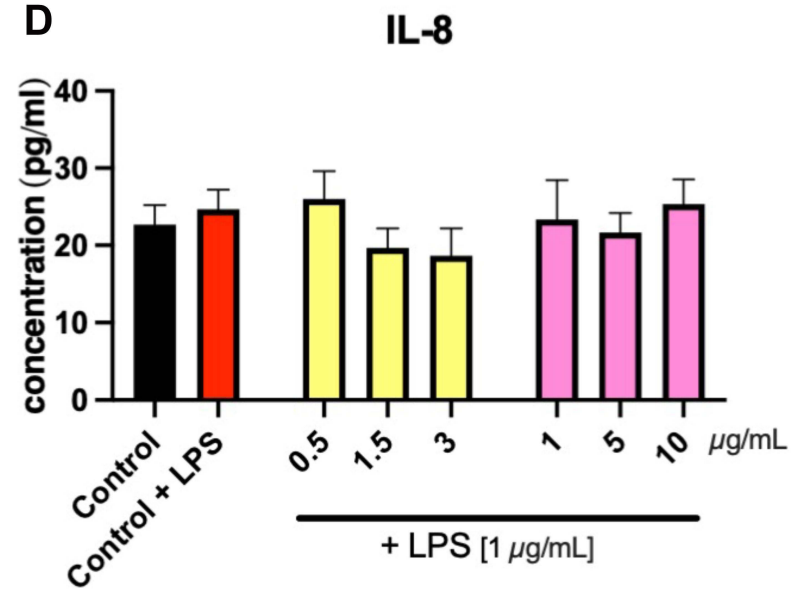

Control

AgNPs-CHL

AgNPs-PEG-MET

Figure 8 Effect of AgNPs-CHL and AgNPs-PEG-MET on cytokine secretion by RAW264.7 cells to medium. Cells were treated with AgNPs-drugs for 24 hours and LPS (I

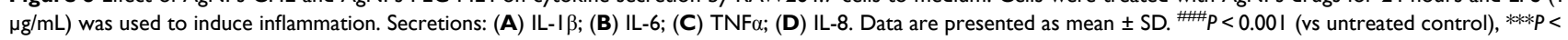
0.00 I (vs control treated with LPS).

\section{Discussion}

The aim of this study was to assess the properties of AgNPs as drug delivery platforms to treat PD. Two types of NPs were examined: AgNPs-CHL and AgNPs-PEGMET. We determined that AgNPs can be effective drug delivery platforms for chlorhexidine and metronidazole. Importantly, they have a synergistic antimicrobial effect and they are non-toxic for mammalian cells at low concentrations. We also found that our NPs have antiinflammatory properties. The conjugates of AgNPs with chlorhexidine and metronidazole were synthesized and tested in an in vitro model for the first time. We used three cell lines which are commonly used to study PD in our experiments: HGF-1 and hFOB1.19, which were used as models of periodontal cells, and RAW264.7, which are commonly used to assess the anti-inflammatory properties of different compounds. ${ }^{53-55}$

\section{Nanoparticles as Drug Delivery Platforms}

Various types of NPs have been described as drug delivery platforms. The implementation of NPs should ensure positive properties, such as reduced toxicity and cost of 


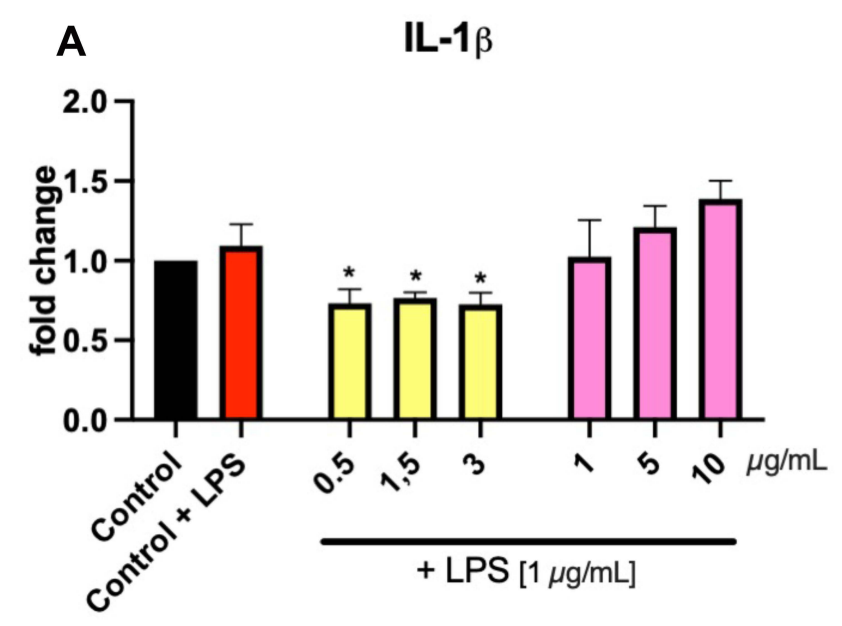

B

IL-6

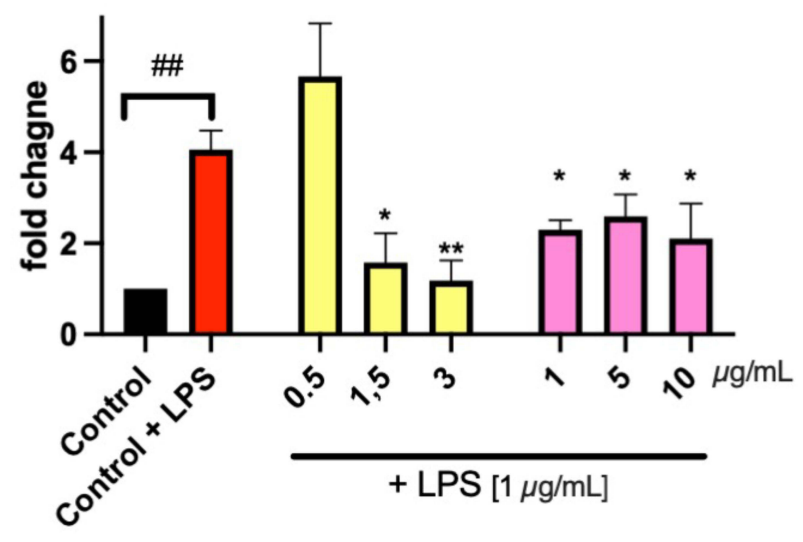

C

TNF $\alpha$
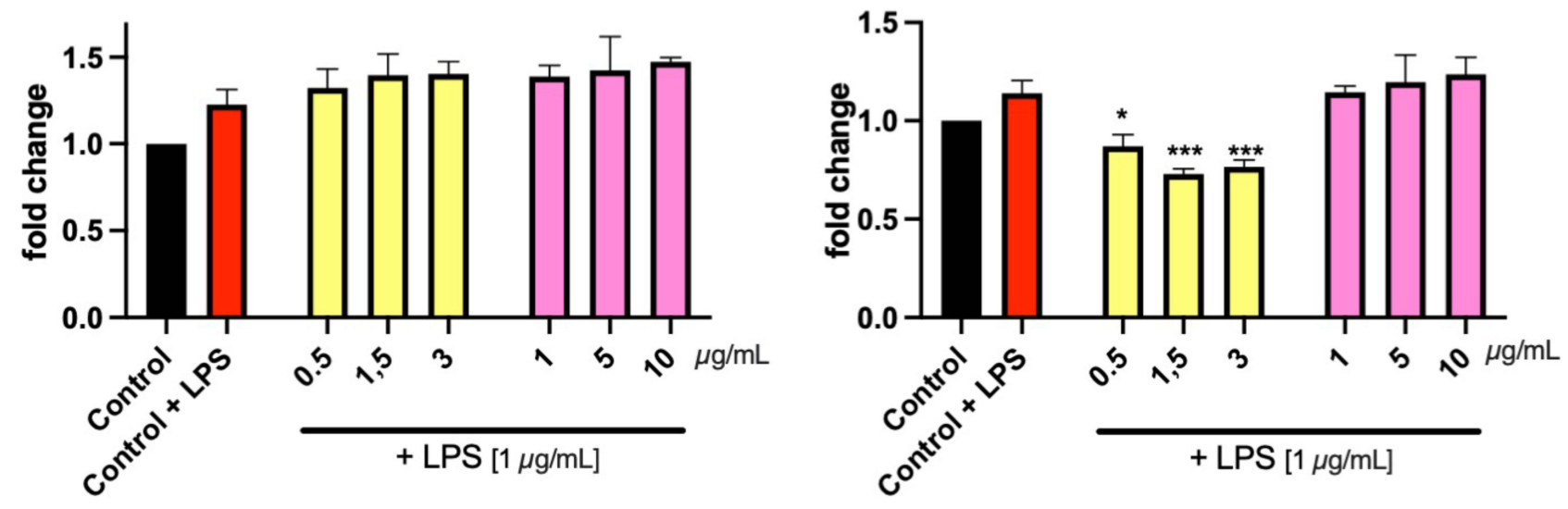

Control $\square$ Control + LPS

AgNPs-CHL $\square$ AgNPs-PEG-MET

Figure 9 Effect of AgNPs-CHL and AgNPs-PEG-MET on intracellular production of cytokines by RAW264.7 cells. Cells were treated with AgNPs-drugs for 24 hours and LPS (I $\mu \mathrm{g} / \mathrm{mL})$ was used to induce inflammation: (A) production of IL-I $\beta$; (B) production of IL-6; (C) production of TNF $\alpha$; (D) production of IL-8. Data are presented as mean \pm SD. ${ }^{\# *} P<0.01$ (vs untreated control), $* P<0.05, * * P<0.01, * * * P<0.00$ I (vs control treated with LPS).

treatment, while increasing drug effectiveness. ${ }^{56}$ Most existing NPs drug delivery platforms are based on gold and AgNPs. ${ }^{57-59}$ We decided to use AgNPs, as published data suggests that they have stronger antimicrobial effects than gold NPs. ${ }^{60,61}$ NPs are often functionalized using glutathione (GSH) or polyethylene glycol (PEG) to increase their biocompatibility. PEG improves water solubility and prevents protein coating of NPs, which increases their half-life in the bloodstream. ${ }^{62,63} \mathrm{We}$ therefore decided to use PEG to link metronidazole molecules to the surfaces of the NPs.

\section{Antimicrobial Properties}

AgNPs are well known for their antimicrobial and antifungal properties. ${ }^{23,24,64}$ The mechanisms of this activity include release of Ag ions, DNA damage, bacterial cell wall lysis, reactive oxygen species generation and enzyme inhibition. ${ }^{65-67}$ AgNPs can also affect the peptidoglycan 


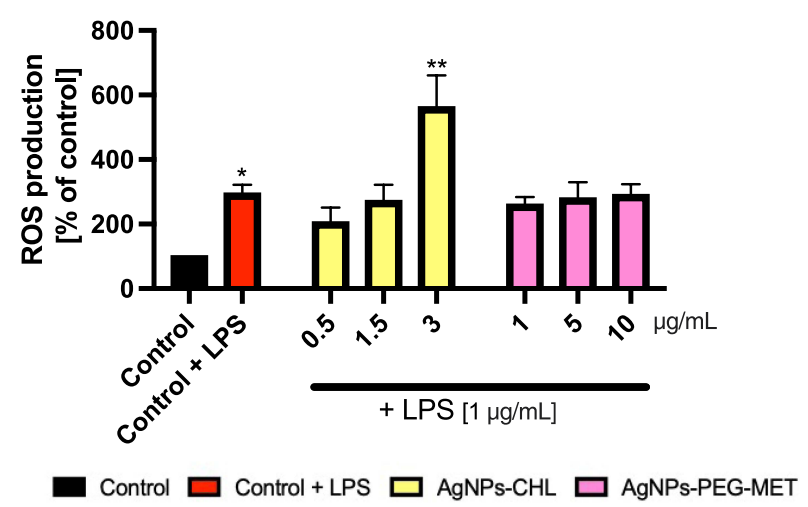

Figure 10 Effect of AgNPs-CHL and AgNPs-PEG-MET on intracellular production of reactive oxygen species in RAW264.7 cells. Cells were treated with AgNPs-drugs for 24 hours and LPS $(\mathrm{I} \mu \mathrm{g} / \mathrm{mL}$ ) was used to induce inflammation. Data are presented as mean $\pm \mathrm{SD}$. $* P<0.05$, $* * P<0.0 \mathrm{l}$ (vs unstimulated control).

structures of the cell wall by disrupting the $\beta$-bonds between $\mathrm{N}$-acetylglucosamine and $\mathrm{N}$-acetylmuramic acids. $^{68}$ We observed synergistic antimicrobial effects caused by the drugs and NPs, indicating that our NPs have strong antimicrobial properties and were more effective than drugs alone in all cases. AgNPs-CHL and AgNPs-MET-PEG were found to be effective against bacteria and fungi, both in planktonic form and as biofilm. MBEC values were higher than MIC values. This is a typical observation, as pathogens in a biofilm are more resistant to treatment due to the complex nature of biofilm. $^{16}$

Different factors may influence the antibacterial properties of AgNPs. Pal et al determined that shape is an important modulator of this activity and proved that Escherichia coli is more susceptible to triangular AgNPs compared to spherical and rod-shaped AgNPs. ${ }^{69}$ Raza et al proved that AgNPs' antimicrobial activity against Pseudomonas aeruginosa and E. coli is size- and shapedependent. Interestingly, spherical AgNPs with smaller sizes were more potent antimicrobials than triangular ones. ${ }^{70}$ AgNPs' antimicrobial activity is also functionalization dependent. Our results indicated that pegylated NPs were less effective. There are a few possible explanations for this. First, we did not examine the effect of AgNPsPEG-MET on anaerobic bacteria strains, but metronidazole is typically more effective on these bacteria than it is on aerobic strains. Second, as mentioned earlier, functionalization by thiolate combined ligands might reduce AgNPs' antimicrobial activity. ${ }^{71}$

Data on AgNPs as antimicrobial drug delivery platforms are limited. To the best of our knowledge, this is the first study to combine AgNPs with chlorhexidine or metronidazole. Deng et al determined that AgNPs and different antibiotics (ampicillin, penicillin, enoxacin, kanamycin, neomycin and tetracycline) had a synergistic antimicrobial effect on Salmonella typhimurium, but they found no chemical bond between the AgNPs and antibiotic molecules, indicating that it was simply a co-exposition. Interestingly, a mixture of AgNPs and antibiotics was found to be more effective than AgNPs or antibiotics alone. ${ }^{72}$ Esmaeillou et al synthesized spherical AgNPs stabilized with thioglycolic acid and conjugated with vancomycin (VAN), expecting the NPs to be effective against multi-antibiotic resistant (MDR) strains. ${ }^{73}$ Combining NPs with an antibiotic significantly decreased the MIC values of the tested strains. The AgNPsVAN were found to be more potent antimicrobial agents than AgNPs or VAN alone against Staphylococcus aureus, E coli (VRE) or $S$. epidermidis (MRSE). ${ }^{73}$ Hur et al achieved similar results, although they found that in some cases conventional antibiotics were more effective than AgNPs conjugated with VAN. $^{74}$ AgNPs were conjugated with ceftriaxone and ciprofloxacin in both studies, the results of which indicated that conjugates of AgNPs and drugs were more effective than the drugs or AgNPs alone. ${ }^{75,76}$ Interestingly, our previous studies showed that functionalizing some AgNPs with capping agents did not severely impact their antimicrobial activity. ${ }^{71}$

\section{Anti-Inflammatory Properties}

Both AgNPs-CHL and AgNPs-PEG-MET have antiinflammatory properties, although those of the former are stronger. Few studies have reported on the antiinflammatory properties of chlorhexidine. Houri- 


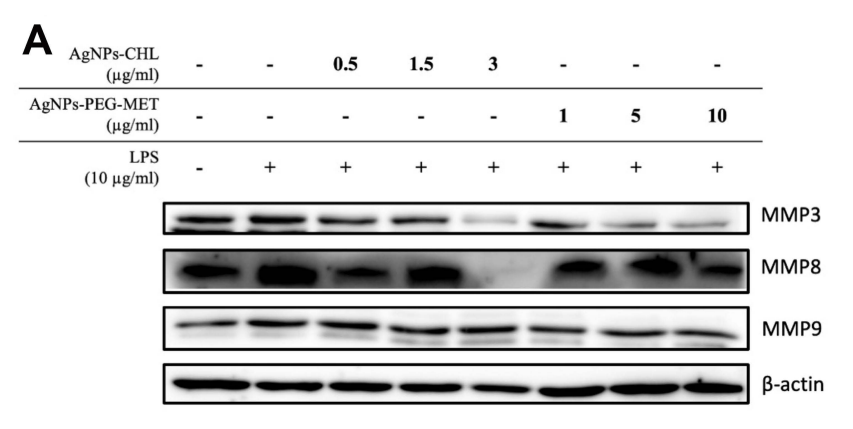

B

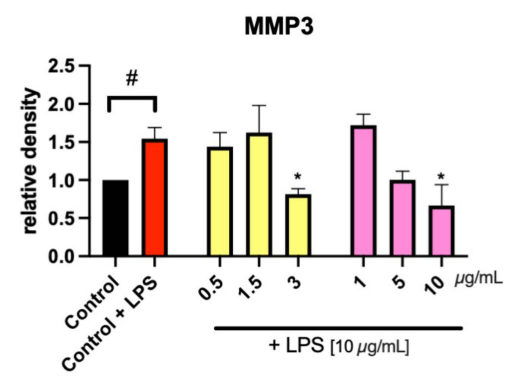

C

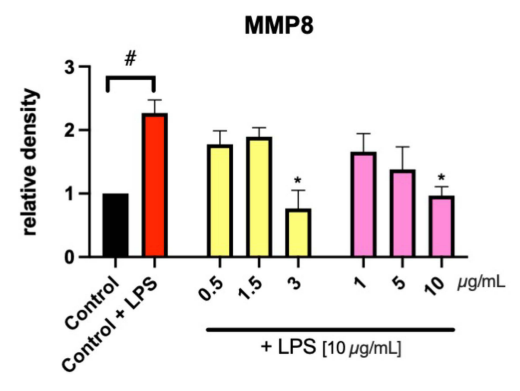

D

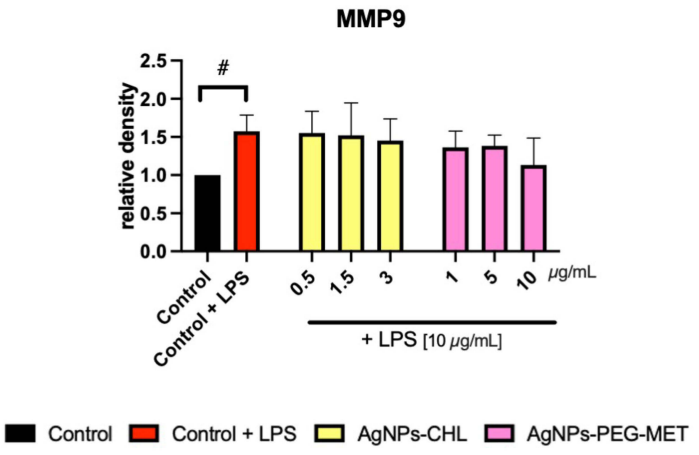

Figure I I Effect of AgNPs-CHL and AgNPs-PEG-MET on metalloproteinase levels in hFOBI. 19 cells. Cells were treated with AgNPs-drugs for 24 hours and LPS (10 $\mu \mathrm{g} / \mathrm{mL}$ ) was used to induce inflammation: (A) representative Western blots; (B) quantification of MMP3 levels; (C) quantification of MMP8 levels; (D) quantification of MMP9 levels. Data are presented as mean \pm SD. ${ }^{\#} P<0.05$ (vs unstimulated control), $* P<0.05$ (vs control treated with LPS).

Haddad et al reported that chlorhexidine can decrease the levels of TNF $\alpha$ and INF $\gamma$ in BALB/c mice with experimentally induced PD and decrease leucocytosis. ${ }^{77} \mathrm{We}$ did not find any reports where metronidazole alone demonstrated anti-inflammatory properties in an in vitro or in vivo model, and some reports indicated that metronidazole does not have anti-inflammatory properties. ${ }^{78}$
Several studies have assessed the anti-inflammatory properties of AgNPs. Two studies confirmed that AgNPs might have stronger anti-inflammatory properties than drugs (specifically, sodium diclofenac). ${ }^{79,80}$ Singh et al reported that $66 \mathrm{~nm}$ green-synthesized AgNPs inhibited the inflammatory response in LPS-stimulated RAW264.7. ${ }^{81}$ They observed decreased levels of nitric oxide (NO) production, cyclooxygenase (COX-2) mRNA, and the expression of the inflammation-related proteins $\mathrm{p}-\mathrm{I} \kappa \mathrm{B}, \mathrm{NF}-\kappa \mathrm{B}$ p-38, p-JNK and $\mathrm{p}$-ERK. ${ }^{81}$ David et al also showed that $40 \mathrm{~nm}$ greensynthesized AgNPs could decrease the production of IL-1 $\beta$ in ultraviolet-light-stimulated human keratinocytes (HaCaT). ${ }^{82}$ AgNPs may decrease ROS, nitric oxide and TNF $\alpha$ production in LPS-stimulated N9 and N27 neuronal cells by the induction of hydrogen-sulfide-synthesizing enzymes. ${ }^{83}$ This effect was more prominent for AgNPs than $\mathrm{AgNO}_{3}$, which indicates that nano-size is an important modulator of biological properties. ${ }^{83}$ Ten-nanometre AgNPs were also reported to decrease levels of TNF $\alpha$ and IL-12 and to decrease the expression of COX-2 in normal human dermal fibroblasts and normal human keratinocytes. ${ }^{84}$ However, Huang et al reported that 3-5 nm AgNPs may trigger inflammation in murine microglia (BV-2) and mouse neuroblastoma cells (N2a): they observed increased levels of IL-1 $\beta$ and translations of proinflammatory genes. ${ }^{85}$ These observations about the anti-inflammatory properties of AgNPs were also confirmed in in vivo studies. ${ }^{86,87}$ Similarly, glutathionestabilized AgNPs may increase the production of IL-6, IL-8 and TNF $\alpha$ in HGF-1 cells. ${ }^{55}$ TNF $\alpha$ expression may also be increased when RAW264.7 cells are treated with $68.9 \mathrm{~nm}$ AgNPs. ${ }^{88}$ Interestingly, a recent study examined the role of highly biocompatible biomimetic scaffold embedding AgNPs in the treatment of oral lesions. ${ }^{89}$ Synthesized material demonstrated both antimicrobial and anti-inflammatory properties, inhibiting the growth of $F$. nucleatum and P. gingivalis and suppressing production of IL-6, IL-8 and TNF $\alpha$ in stimulated THP1 cells (human monocytic leukaemia). ${ }^{89}$

We also observed that AgNPs-CHL and AgNPs-PEGMET decreased levels of MMP3 and MMP8, which suggests that AgNPs inhibit tissue degeneration and may slow disease progression. Both drugs used in this study can impact MMP activity. Chlorhexidine inhibits MMP2, MMP8 and MMP $9,{ }^{90}$ while metronidazole decreases the activity of proMMP-3. ${ }^{91}$ Frankova et al reported that 10 $\mathrm{nm}$ AgNPs did not affect MMP1 and MMP3 expression in normal human dermal fibroblasts and normal human keratinocytes. ${ }^{84}$ AgNPs $68.9 \mathrm{~nm}$ in size may increase 
mRNA levels of MMP3, MMP11 and MMP19 in RAW264.7 cells. ${ }^{88}$ AgNPs embedded in a specific polysaccharide (EPS) can decrease the enzymatic activity of MMP2 MMP9 from SKBR3 (human breast adenocarcinoma) cells. ${ }^{92}$ Two- to four-nanometre AgNPs can also reduce the enhancement of MMP1 and MMP2 from platelet-rich plasma. This effect was capping-agent-dependent and glutathione stabilized, and pegylated AgNPs were found to be more potent than AgNPs capped with lipoic acid. $^{93}$

\section{Cytocompatibility}

The synthesized conjugates exhibited relatively low cytotoxicity at relatively high concentrations. Importantly, AgNPs-CHL and AgNPs-PEG-MET have beneficial properties in nontoxic concentrations. Several reports have indicated that AgNPs can decrease the viability of human cells. AgNPs are cytotoxic to cell types such as gingival fibroblasts, osteoblasts, dental pulp, muscles and others found in the oral cavity and gastrointestinal tract. ${ }^{36,94-96}$ The main cytotoxicity mechanisms of AgNPs are mitochondrial disruption and ROS generation, which lead to DNA and protein damage. ${ }^{97}$ AgNPs can also affect membrane potential and have a lytic effect. ${ }^{97}$ Dysfunction of important cellular processes may cause homeostasis imbalance and programmed cell death.

Several factors influence AgNPs cytotoxicity. Smaller AgNPs are typically more cytotoxic than larger ones. ${ }^{98}$ Their shape is also important. Soleimani et al reported that AgNPs with sharper geometry were more cytotoxic, while spherical ones had the least effect on cell viability. ${ }^{99}$ Functionalization may also impact the safety profile of AgNPs, which is essential in our case. We noticed that AgNPs-PEG-MET had a weaker effect on cell viability than AgNPs-CHL. Pegylated AgNPs are usually safer than non-thiolate-functionalized AgNPs, which was proven by our team in several cellular models (gingival fibroblasts, human umbilical vein endotheliocytes and human platelets). ${ }^{71,93}$ This observation is consistent with the data reported in the literature. Soenen et al proved that pegylated gold NPs (AuNPs) have a lesser effect on cell morphology, ROS generation and cell death induction in HUVEC cells than non-pegylated ones. ${ }^{100} \mathrm{Yu}$ et al reported a similar observation, but for iron oxide NPs. ${ }^{101}$

Several studies have suggested that AgNPs can be internalized by eukaryotic cells. Diffusion through cellular membrane, endocytosis or phagocytosis are thought to be the main internalization mechanisms of AgNPs. ${ }^{97}$
Sengstock et al proved that human mesenchymal stem cells can uptake 80-nm AgNPs, which were found inside these cells but not in the nucleus. ${ }^{102}$ A similar observation was described for 5-nm AgNPs, but for human mesenchymal stem cells and osteoblasts. ${ }^{103}$ However, 30-nm AgNPs can enter HaCaT cells and penetrate the nucleus. ${ }^{104}$ We observed that AgNPs-CHL and AgNPsPEG-MET were internalized by the cells we tested, but the NPs did not penetrate the nucleus and did not cause major ultrastructure changes.

Interestingly, pegylated NPs were found in the autophagic vacuoles, whereas AgNPs-CHL were localized in the cytosol. Guo et al recorded a similar observation, although they used a higher concentration than we did. $^{105}$ This phenomenon may be partially explained by the differences in cytotoxicity of the two types of NPs. Enclosing AgNPs-PEG-MET in autophagic vacuoles may limit their contact with other organelles, thus having a protective effect, and the internalization of the NPs may coat them with proteins, which will influence their surface properties. ${ }^{106}$

\section{Safety of Potential Applications}

We are aware that the cytotoxicity of AgNPs-CHL may be concerning, but it must be remembered that no clinically used substances are free of side effects. AgNPs may thus be beneficial drug delivery platforms. Due to the synergistic effects of drugs and AgNPs, lower concentrations of pharmaceuticals may be used, which will potentially decrease their side effects. We also observed high selectivity index values. There is no consensus regarding which SI values should be the cut-off point: some studies suggest that compounds with an SI $>3$ are worth further investigation, while others suggest that an SI $>10$ is preferable. ${ }^{107,108}$ Both types of AgNPs used in this study have at least two SI values $>10$.

The antibacterial agents used in this study, chlorhexidine and metronidazole, are cytotoxic. Babich et al examined the impact of chlorhexidine on epithelial gingival cell line (S-G), human gingival fibroblast (HGF-1) and found that chlorhexidine decreased the viability of the cell lines tested in a concentration- and time-dependent manner by disrupting cell membranes and calcium homeostasis disruption. ${ }^{109}$ Hidalgo et al reported that chlorhexidine could decrease ATP production and proliferation rate in human dermal fibroblasts. ${ }^{110}$ Even as concentrations of chlorhexidine as low as $0.0001 \%$ depleted ATP production in the cells. ${ }^{110}$ Chlorhexidine can also cause apoptosis and 
necrosis and damage DNA and ROS generation, which was proven in a RAW264.7 macrophage model. ${ }^{111}$

Ferreira et al reported time- and concentrationdependent metronidazole cytotoxicity against human gingival fibroblasts (FMM1). Concentrations of metronidazole as low as $5 \mathrm{mg} / \mathrm{L}$ decreased the viability of FMM1 cells. However, visible changes in cell morphology were observed following treatment with $150 \mathrm{mg} / \mathrm{L} .{ }^{112}$

\section{Conclusion}

We designed and synthesized novel conjugates of AgNPs with chlorhexidine or metronidazole. AgNPs-CHL and AgNPs-PEG-MET exhibit potent antimicrobial, antibiofilm and anti-inflammatory effects. The safety of their potential clinical usage was evaluated in in vitro models, which showed that NPs may have beneficial properties in non-toxic concentrations. Our results prove that AgNPs are effective drug delivery platforms for chlorhexidine and metronidazole. AgNPs-CHL and AgNPs-PEG-MET may be possible therapeutic options for PD. Our findings need to be evaluated in in vivo studies.

\section{Abbreviations}

AgNPs-CHL, silver nanoparticles conjugated with chlorhexidine; AgNPs-PEG-MET, silver nanoparticles stabilized with poly(ethylene glycol) and conjugated with metronidazole; AgNPs, silver nanoparticles; DLS, dynamic light scattering; $\mathrm{IC}_{50}$, half-maximal inhibitory concentration; IL-1 $\beta$, inteleukin $1 \beta$; Il-6, interleukin 6; IL8 , interleukin 8; LPS, lipopolysaccharide; MBEC, minimum biofilm eradication concentration; MIC, minimum inhibitory concentration; MMP, metalloproteinase; NPs, nanoparticles; PD, periodontal disease; PEG, poly(ethylene glycol); ROS, reactive oxygen species; SI, selectivity index; TEM, transmission electron microscopy; TGA, thermogravimetric analysis; $\mathrm{TNF} \alpha$, tumour necrosis factor.

\section{Ethical Statement}

According to local and European Union law, this study protocol did not require ethical approval from any institutional board. We received written consent for Somersault1824's team (I. Lahortiga, and L. Cox) to use the images they designed under a CC BY open access license in all printed and digital formats.

\section{Acknowledgments}

This work was supported by PRELUDIUM grant 2017/27/ N/NZ7/0267 from the Polish National Science Centre (PI of the grant - EB, Scientific supervisor of the grant - IIS) and grant St-54 from the Medical University of Gdansk (PI - IIS). Some elements of our figures were downloaded from the website www.somersault1824.com and were used in this paper with the permission of the creators. The authors are grateful for this kindness. The authors also would like to thank Elise Robolin (Lycée NiepceBalleure, Chalon-sur-Saône, France), Suzan Amin Abdelrazek and Mai Maher Ibrahim (Military Medical Academy, Cairo, Egypt), who carried out their internships at our lab, for their assistance with part of the reported syntheses.

\section{Disclosure}

The authors report no conflicts of interest in this work.

\section{References}

1. Tonetti MS, Jepsen S, Jin L, Otomo-Corgel J. Impact of the global burden of periodontal diseases on health, nutrition and wellbeing of mankind: a call for global action. $J$ Clin Periodontol. 2017;44(5):456-462. doi:10.1111/jcpe.12732

2. Kinane DF. Causation and pathogenesis of periodontal disease. Periodontol 2000. 2001;25(1):8-20. doi:10.1034/j.16000757.2001.22250102.x

3. Lovegrove JM. Dental plaque revisited: bacteria associated with periodontal disease. $J N Z$ Z Soc Periodontol. 2004;(87):7-21.

4. Dani S, Prabhu A, Chaitra K, Desai N, Patil S, Rajeev R. Assessment of Streptococcus mutans in healthy versus gingivitis and chronic periodontitis: a clinico-microbiological study. Contemp Clin Dent. 2016;7(4):529-534. doi:10.4103/0976237X.194114

5. O'Connor AM, McManus BA, Kinnevey PM, et al. Significant enrichment and diversity of the Staphylococcal arginine catabolic mobile element ACME in Staphylococcus epidermidis isolates from subgingival peri-implantitis sites and periodontal pockets. Front Microbiol. 2018;9(JUL):1558. doi:10.3389/fmicb.2018.01558

6. Kim G-Y-Y, Lee CH. Antimicrobial susceptibility and pathogenic genes of Staphylococcus aureus isolated from the oral cavity of patients with periodontitis. J Periodontal Implant Sci. 2015;45 (6):223-228. doi:10.5051/jpis.2015.45.6.223

7. Souto R, Silva-Boghossian CM, Colombo APV. Prevalence of Pseudomonas aeruginosa and Acinetobacter spp. in subgingival biofilm and saliva of subjects with chronic periodontal infection. Brazilian J Microbiol. 2014;45(2):495-501. doi:10.1590/S151783822014000200017

8. Zaatout N. Presence of non-oral bacteria in the oral cavity. Arch Microbiol. 2021;203(6):2747-2760. doi:10.1007/s00203-02102300-y

9. Jabri B, Iken M, Achmit M, Rida S, Ennibi OK. Occurrence of Candida albicans in periodontitis. Int $J$ Dent. 2021;2021:5589664. doi:10.1155/2021/5589664

10. Schwarzberg K, Le R, Bharti B, et al. The personal human oral microbiome obscures the effects of treatment on periodontal disease. PLoS One. 2014;9(1):e86708. doi:10.1371/journal.pone.0086708

11. Solderer A, Kaufmann M, Hofer D, Wiedemeier D, Attin T, Schmidlin PR. Efficacy of chlorhexidine rinses after periodontal or implant surgery: a systematic review. Clin Oral Investig. 2019;23(1):21-32. doi:10.1007/s00784-018-2761-y 
12. Zupancic S, Kocbek P, Baumgartner S, Kristl J. Contribution of nanotechnology to improved treatment of periodontal disease. Curr Pharm Des. 2015;21(22):3257-3271. doi:10.2174/ 1381612821666150531171829

13. Romeo U, Libotte F, Palaia G, et al. Oral soft tissue wound healing after laser surgery with or without a pool of amino acids and sodium hyaluronate: a randomized clinical study. Photomed Laser Surg. 2014;32(1):10-16. doi:10.1089/ pho.2013.3509

14. Blomgren J, Beiggren U, Jontell M. Fluconazole versus nystatin in the treatment of oral candidosis. Acta Odontol Scand. 1998;56 (4):202-205. doi:10.1080/00016359850142790

15. Diz Dios P, Tomás Carmona I, Limeres Posse J, Medina Henríquez J, Fernández Feijoo J, Álvarez Fernández M. Comparative efficacies of amoxicillin, clindamycin, and moxifloxacin in prevention of bacteremia following dental extractions. Antimicrob Agents Chemother. 2006;50 (9):2996-3002. doi:10.1128/AAC.01550-05

16. Saginur R, St. Denis M, Ferris W, et al. Multiple combination bactericidal testing of staphylococcal biofilms from implant-associated infections. Antimicrob Agents Chemother. 2006;50(1):55-61. doi:10.1128/AAC.50.1.55-61.2006

17. Wetzel C, Lonneman M, Wu C. Polypharmacological drug actions of recently FDA approved antibiotics. Eur J Med Chem. 2021;209:112931. doi:10.1016/j.ejmech.2020.112931

18. Hulla JE, Sahu SC, Hayes AW. Nanotechnology: history and future. Hum Exp Toxicol. 2015;34(12):1318-1321. doi:10.1177/ 0960327115603588

19. Noronha VT, Paula AJ, Durán G, et al. Silver nanoparticles in dentistry. Dent Mater. 2017;33(10):1110-1126. doi:10.1016/j. dental.2017.07.002

20. Martinez-Gutierrez F, Boegli L, Agostinho A, et al. Anti-biofilm activity of silver nanoparticles against different microorganisms. Biofouling. 2013;29(6):651-660. doi:10.1080/ 08927014.2013.794225

21. Craciunescu O, Seciu AM, Manoiu VS, et al. Biosynthesis of silver nanoparticles in collagen gel improves their medical use in periodontitis treatment. Part Sci Technol. 2019;37(6):757-763. doi:10.1080/02726351.2018.1455780

22. Azócar MI, Alarcón R, Castillo A, Blamey JM, Walter M, Paez M. Capping of silver nanoparticles by anti-inflammatory ligands: antibacterial activity and superoxide anion generation. J Photochem Photobiol B Biol. 2019;193:100-108. doi:10.1016/ j.jphotobiol.2019.02.005

23. Mohanty S, Mishra S, Jena P, Jacob B, Sarkar B, Sonawane A. An investigation on the antibacterial, cytotoxic, and antibiofilm efficacy of starch-stabilized silver nanoparticles. Nanomedicine. 2012;8(6):916-924. doi:10.1016/j.nano.2011.11.007

24. Franci G, Falanga A, Galdiero S, et al. Silver nanoparticles as potential antibacterial agents. Molecules. 2015;20(5):8856-8874. doi: $10.3390 /$ molecules20058856

25. Mathur P, Jha S, Ramteke S, Jain NK. Pharmaceutical aspects of silver nanoparticles. Artif Cells Nanomed Biotechnol. 2018;46 (sup1):115-126. doi:10.1080/21691401.2017.1414825

26. Steckiewicz KP, Inkielewicz-Stepniak I. Modified nanoparticles as potential agents in bone diseases: cancer and implant-related complications. Nanomaterials. 2020;10(4):658. doi:10.3390/ nano10040658

27. Kuyyakanond T, Quesnel LB. The mechanism of action of chlorhexidine. FEMS Microbiol Lett. 1992;100(1-3):211-215. doi:10.1111/j.1574-6968.1992.tb14042.x

28. Sigeti JS, Guiney DG, Davis CE. Mechanism of action of metronidazole on bacteroides fragilis. J Infect Dis. 1983;148 (6):1083-1089. doi:10.1093/infdis/148.6.1083
29. Panpaliya NP, Dahake PT, Kale YJ, et al. In vitro evaluation of antimicrobial property of silver nanoparticles and chlorhexidine against five different oral pathogenic bacteria. Saudi Dent $J$. 2019;31(1):76-83. doi:10.1016/j.sdentj.2018.10.004

30. Myronov P, Sulaieva O, Korniienko V, et al. Combination of chlorhexidine and silver nanoparticles: an efficient wound infection and healing control system. Bionanoscience. 2021;11 (2):256-268. doi:10.1007/s12668-021-00834-5

31. Otera J, Nishikido J. Esterification Methods, Reactions, and Applications. 2nd ed. Weinheim, Germany: Wiley; 2010.

32. Krzywicka A, Megiel E. Silver-polystyrene (Ag/ps) nanocomposites doped with polyvinyl alcohol (pva) - fabrication and bactericidal activity. Nanomaterials. 2020;10(11):1-15. doi:10.3390/ nano10112245

33. Fedorczyk M, Krzywicka A, Cieciórski P, Romański J, Megiel E. A novel strategy for the synthesis of amphiphilic and thermoresponsive Poly(N-isopropylacrylamide)-b-polystyrene block copolymers via ATRP. Polymers (Basel). 2019;11(9):1484. doi:10.3390/polym11091484

34. Wayne PA. Methods for Dilution Antimicrobial Susceptibility Tests for Bacteria That Grow Aerobically: Approved Standard. Vol. 32. 9th ed. Clinical and Laboratory Standards Institute (CLSI); 2012. doi:10.4103/0976-237X.91790

35. Clinical and Laboratory Standards Institute (CLSI). Reference method for broth dilution antifungal susceptibility testing of yeasts: approved standards. 2nd ed. In: CLSI Document M27-2a 2002. Wayne, PA: CLSI; 2002.

36. Steckiewicz KP, Zwara J, Jaskiewicz M, et al. Shape-depended biological properties of Ag 3 PO 4 microparticles: evaluation of antimicrobial properties and cytotoxicity in in vitro modelsafety assessment of potential clinical usage. Oxid Med Cell Longev. 2019;2019(art id 6740325):1-19. doi:10.1155/2019/ 6740325

37. Neubauer D, Jaśkiewicz M, Sikorska E, et al. Effect of disulfide cyclization of ultrashort cationic lipopeptides on antimicrobial activity and cytotoxicity. Int $J$ Mol Sci. 2020;21(19):1-30. doi:10.3390/ijms21197208

38. Neubauer D, Jaśkiewicz M, Bauer $M$, et al. Biological and physico-chemical characteristics of arginine-rich peptide gemini surfactants with lysine and cystine spacers. Int J Mol Sci. 2021;22 (7):3299. doi:10.3390/ijms22073299

39. Steckiewicz KP, Barcinska E, Malankowska A, et al. Impact of gold nanoparticles shape on their cytotoxicity against human osteoblast and osteosarcoma in in vitro model. Evaluation of the safety of use and anti-cancer potential. J Mater Sci Mater Med. 2019;30(22):1-15. doi:10.1007/s10856-019-6221-2

40. Moro C, Palacios I, Lozano M, et al. Anti-inflammatory activity of methanolic extracts from edible mushrooms in LPS activated RAW 264.7 macrophages. Food Chem. 2012;130(2):350-355. doi:10.1016/j.foodchem.2011.07.049

41. Feng Y, Wang L, Ma X, et al. Effect of hCMSCs and liraglutide combination in ALI through cAMP/PKAc/ $\beta$-catenin signaling pathway. Stem Cell Res Ther. 2020;11(1):1-12. doi:10.1186/ s13287-019-1492-6

42. Sun J, Nemoto E, Hong G, Sasaki K. Modulation of stromal cellderived factor 1 alpha (SDF-1 $\alpha$ ) and its receptor CXCR4 in Porphyromonas gingivalis-induced periodontal inflammation. BMC Oral Health. 2016. doi:10.1186/s12903-016-0250-8

43. De Colli M, Tortorella P, Agamennone M, et al. Bisphosfonate matrix metalloproteinase inhibitors for the treatment of periodontitis: an in vitro study. Int J Mol Med. 2018;42(1):651-657. doi:10.3892/ijmm.2018.3641

44. Li X, Wang X, Luan Q-X. Hyperresponsiveness of human gingival fibroblasts from patients with aggressive periodontitis against bacterial lipopolysaccharide. Exp Ther Med. 2021;21(5):1-7. doi:10.3892/etm.2021.9861 
45. Yu Y, Li X, Mi J, et al. Resveratrol suppresses matrix metalloproteinase-2 activation induced by lipopolysaccharide in mouse osteoblasts via interactions with AMP-activated protein kinase and suppressor of cytokine signaling 1. Molecules. 2018;23(9):2327. doi:10.3390/molecules23092327

46. Sherma J, Fried B, eds. Handbook of Thin-Layer Chromatography (Chromatographic Science). 3rd ed. New York: Marcel Dekker; 2003.

47. Zhang XF, Liu ZG, Shen W, Gurunathan S. Silver nanoparticles: synthesis, characterization, properties, applications, and therapeutic approaches. Int J Mol Sci. 2016;17(9):1534. doi:10.3390/ ijms 17091534

48. Restrepo CV, Villa CC. Synthesis of silver nanoparticles, influence of capping agents, and dependence on size and shape: a review. Environ Nanotechnol Monit Manag. 2021;15:100428. doi:10.1016/j.enmm.2021.100428

49. Krystosiak P, Tomaszewski W, Megiel E. High-density polystyrene-grafted silver nanoparticles and their use in the preparation of nanocomposites with antibacterial properties. J Colloid Interface Sci. 2017;498:9-21. doi:10.1016/j.jcis.2017.03.041

50. Gozdziewska M, Cichowicz G, Markowska K, Zawada K, Megiel E. Nitroxide-coated silver nanoparticles: synthesis, surface physicochemistry and antibacterial activity. RSC $A d v .2015 ; 5$ (72):58403-58415. doi:10.1039/c5ra09366j

51. Le Ouay B, Stellacci F. Antibacterial activity of silver nanoparticles: a surface science insight. Nano Today. 2015;10(3):339-354. doi:10.1016/j.nantod.2015.04.002

52. Yang HL, Lin SW, Lee CC, et al. Induction of Nrf2-mediated genes by Antrodia salmonea inhibits ROS generation and inflammatory effects in lipopolysaccharide-stimulated RAW264.7 macrophages. Food Funct. 2015;6(1):230-241. doi:10.1039/c4fo00869c

53. Morimoto Y, Kikuchi K, Ito T, et al. MK615 attenuates Porphyromonas gingivalis lipopolysaccharide-induced pro-inflammatory cytokine release via MAPK inactivation in murine macrophage-like RAW264.7 cells. Biochem Biophys Res Commun. 2009;389(1):90-94. doi:10.1016/j.bbrc.2009.08.103

54. Nebel D, Svensson D, Arosenius K, Larsson E, Jönsson D, Nilsson BO. 1 $\alpha, 25$-dihydroxyvitamin D3 promotes osteogenic activity and downregulates proinflammatory cytokine expression in human periodontal ligament cells. J Periodontal Res. 2015;50 (5):666-673. doi:10.1111/jre. 12249

55. Zorraquín-Peña I, Cueva C, de Llano DG, Bartolomé B, MorenoArribas MV. Glutathione-stabilized silver nanoparticles: antibacterial activity against periodontal bacteria, and cytotoxicity and inflammatory response in oral cells. Biomedicines. 2020;8 (10):375. doi:10.3390/BIOMEDICINES8100375

56. De Jong WH, Borm PJA. Drug delivery and nanoparticles: applications and hazards. Int J Nanomedicine. 2008;3(2):133-149. doi:10.2147/ijn.s596

57. Steckiewicz KP, Barcińska E, Sobczak K, Tomczyk E, Wójcik M, Inkielewicz-Stepniak I. Assessment of anti-tumor potential and safety of application of glutathione stabilized gold nanoparticles conjugated with chemotherapeutic. Int J Med Sci. 2020;17 (6):824-833. doi:10.7150/ijms.40159

58. Paciotti GF, Kingston DGI, Tamarkin L. Colloidal gold nanoparticles: a novel nanoparticle platform for developing multifunctional tumor-targeted drug delivery vectors. Drug Dev Res. 2006;67(1):47-54. doi:10.1002/ddr.20066

59. Austin LA, MacKey MA, Dreaden EC, El-Sayed MA. The optical, photothermal, and facile surface chemical properties of gold and silver nanoparticles in biodiagnostics, therapy, and drug delivery. Arch Toxicol. 2014;88(7):1391-1417. doi:10.1007/s00204-014-1245-3

60. Hernández-Sierra JF, Ruiz F, Cruz Pena DC, et al. The antimicrobial sensitivity of Streptococcus mutans to nanoparticles of silver, zinc oxide, and gold. Nanomedicine. 2008;4(3):237-240. doi:10.1016/j.nano.2008.04.005
61. Khatoon UT, Rao GV, Mohan MK, Ramanaviciene A, Ramanavicius A. Comparative study of antifungal activity of silver and gold nanoparticles synthesized by facile chemical approach. $J$ Environ Chem Eng. 2018;6(5):5837-5844. doi:10.1016/j.jece.2018.08.009

62. Pan Y, Neuss S, Leifert A, et al. Size-dependent cytotoxicity of gold nanoparticles. Small. 2007;3(11):1941-1949. doi:10.1002/ smll.200700378

63. Dreaden EC, Alkilany AM, Huang X, Murphy CJ, El-Sayed MA. The golden age: gold nanoparticles for biomedicine. Chem Soc Rev. 2012;41(7):2740-2779. doi:10.1039/c1cs15237h

64. Dos Santos CA, Seckler MM, Ingle AP, et al. Silver nanoparticles: therapeutical uses, toxicity, and safety issues. J Pharm Sci. 2014;103(7):1931-1944. doi:10.1002/jps.24001

65. Morones JR, Elechiguerra JL, Camacho A, et al. The bactericidal effect of silver nanoparticles. Nanotechnology. 2005;16 (10):2346-2353. doi:10.1088/0957-4484/16/10/059

66. Kim JH, Kuk E, Yu KN, et al. Antimicrobial effects of silver nanoparticles. Nanomedicine. 2007;3(1):95-101. doi:10.1016/j. nano.2006.12.001

67. Pereira L, Dias N, Carvalho J, Fernandes S, Santos C, Lima N. Synthesis, characterization and antifungal activity of chemically and fungal-produced silver nanoparticles against Trichophyton rubrum. J Appl Microbiol. 2014;117(6):1601-1613. doi:10.1111/jam.12652

68. Mirzajani F, Ghassempour A, Aliahmadi A, Esmaeili MA. Antibacterial effect of silver nanoparticles on Staphylococcus aureus. Res Microbiol. 2011;162(5):542-549. doi:10.1016/j. resmic.2011.04.009

69. Pal S, Tak YK, Song JM. Does the antibacterial activity of silver nanoparticles depend on the shape of the nanoparticle? A study of the gram-negative bacterium Escherichia coli. Appl Environ Microbiol. 2007;73(6):1712-1720. doi:10.1128/ AEM.02218-06

70. Raza MA, Kanwal Z, Rauf A, Sabri AN, Riaz S, Naseem S. Sizeand shape-dependent antibacterial studies of silver nanoparticles synthesized by wet chemical routes. Nanomaterials. 2016;6 (4):74. doi:10.3390/nano6040074

71. Niska K, Knap N, Kędzia A, Jaskiewicz M, Kamysz W, Inkielewicz-Stepniak I. Capping agent-dependent toxicity and antimicrobial activity of silver nanoparticles: an in vitro study. concerns about potential application in dental practice. Int $J$ Med Sci. 2016;13(10):772-782. doi:10.7150/ijms.16011

72. Deng H, McShan D, Zhang Y, et al. Mechanistic study of the synergistic antibacterial activity of combined silver nanoparticles and common antibiotics. Environ Sci Technol. 2016;50 (16):8840-8848. doi:10.1021/acs.est.6b00998

73. Esmaeillou M, Zarrini G, Rezaee MA, Mojarrad JS, Bahadori A. Vancomycin capped with silver nanoparticles as an antibacterial agent against multi-drug resistance bacteria. Adv Pharm Bull. 2017;7(3):479-483. doi:10.15171/apb.2017.058

74. Hur YE, Park Y. Vancomycin-functionalized gold and silver nanoparticles as an antibacterial nanoplatform against methicillin-resistant staphylococcus aureus. $J$ Nanosci Nanotechnol. 2016;16(6):6393-6399. doi:10.1166/jnn.2016. 12393

75. Harshiny M, Matheswaran M, Arthanareeswaran G, Kumaran S, Rajasree S. Enhancement of antibacterial properties of silver nanoparticles-ceftriaxone conjugate through Mukia maderaspatana leaf extract mediated synthesis. Ecotoxicol Environ Saf. 2015;121:135-141. doi:10.1016/j. ecoenv.2015.04.041

76. Nisar M, Khan SA, Qayum M, et al. Robust synthesis of ciprofloxacin-capped metallic nanoparticles and their urease inhibitory assay. Molecules. 2016;21(4):411. doi:10.3390/ molecules21040411 
77. Houri-Haddad Y, Halabi A, Soskolne WA. Inflammatory response to chlorhexidine, minocycline $\mathrm{HCl}$ and doxycycline $\mathrm{HCl}$ in an in vivo mouse model. J Clin Periodontol. 2008;35(9):783-788. doi:10.1111/j.1600-051X.2008.01290.x

78. Garrido-Mesa N, Camuesco D, Arribas B, et al. The intestinal anti-inflammatory effect of minocycline in experimental colitis involves both its immunomodulatory and antimicrobial properties. Pharmacol Res. 2011;63(4):308-319. doi:10.1016/j. phrs.2010.12.011

79. Jyoti K, Arora D, Fekete G, Lendvai L, Dogossy G, Singh T. Antibacterial and anti-inflammatory activities of Cassia fistula fungal broth-capped silver nanoparticles. Mater Technol. 2020. doi:10.1080/10667857.2020.1802841

80. Vijayakumar S, Malaikozhundan B, Saravanakumar K, Durán-Lara EF, Wang MH, Vaseeharan B. Garlic clove extract assisted silver nanoparticle-antibacterial, antibiofilm, antihelminthic, anti-inflammatory, anticancer and ecotoxicity assessment. J Photochem Photobiol B Biol. 2019;198:111558. doi:10.1016/j.jphotobiol.2019.111558

81. Singh $\mathrm{P}, \mathrm{Ahn} \mathrm{S}$, Kang JP, et al. In vitro anti-inflammatory activity of spherical silver nanoparticles and monodisperse hexagonal gold nanoparticles by fruit extract of Prunus serrulata: a green synthetic approach. Artif Cells Nanomed Biotechnol. 2018;46(8):2022-2032. doi:10.1080/ 21691401.2017.1408117

82. David L, Moldovan B, Vulcu A, et al. Green synthesis, characterization and anti-inflammatory activity of silver nanoparticles using European black elderberry fruits extract. Colloids Surfaces $B$ Biointerfaces. 2014;122:767-777. doi:10.1016/j.colsurfb. 2014.08.018

83. Gonzalez-Carter DA, Leo BF, Ruenraroengsak P, et al. Silver nanoparticles reduce brain inflammation and related neurotoxicity through induction of $\mathrm{H} 2$ S-synthesizing enzymes. Sci Rep. 2017;7(1):1-14. doi:10.1038/srep42871

84. Franková J, Pivodová V, Vágnerová H, Juráňová J, Ulrichová J. Effects of silver nanoparticles on primary cell cultures of fibroblasts and keratinocytes in a wound-healing model. $J$ Appl Biomater Funct Mater. 2016;14(2):e137-e142. doi:10.5301/ jabfm.5000268

85. Huang CL, Hsiao IL, Lin HC, Wang CF, Huang YJ, Chuang CY. Silver nanoparticles affect on gene expression of inflammatory and neurodegenerative responses in mouse brain neural cells. Environ Res. 2015;136:253-263. doi:10.1016/j.envres.2014. 11.006

86. Hebeish A, El-Rafie MH, EL-Sheikh MA, Seleem AA, ElNaggar ME. Antimicrobial wound dressing and anti-inflammatory efficacy of silver nanoparticles. Int $\mathrm{J}$ Biol Macromol. 2014;65:509-515. doi:10.1016/j.ijbiomac. 2014.01.071

87. Zhang S, Liu X, Wang H, Peng J, Wong KKY. Silver nanoparticle-coated suture effectively reduces inflammation and improves mechanical strength at intestinal anastomosis in mice. J Pediatr Surg. 2014;49(4):606-613. doi:10.1016/j. jpedsurg.2013.12.012

88. Park EJ, Yi J, Kim Y, Choi K, Park K. Silver nanoparticles induce cytotoxicity by a Trojan-horse type mechanism. Toxicol Vitr. 2010;24(3):872-878. doi:10.1016/j.tiv.2009.12.001

89. Craciunescu O, Seciu AM, Zarnescu O. In vitro and in vivo evaluation of a biomimetic scaffold embedding silver nanoparticles for improved treatment of oral lesions. Mater Sci Eng C. 2021;123:112015. doi:10.1016/J.MSEC.2021.112015

90. Gendron R, Grenier D, Sorsa T, Mayrand D. Inhibition of the activities of matrix metalloproteinases 2, 8, and 9 by chlorhexidine. Clin Diagn Lab Immunol. 1999;6(3):437-439. doi:10.1128/cdli.6.3.437-439.1999
91. Kim H-J, Lim K-J, Kim S-M, Kim B-O, Han K-Y. The inhibitory effect of metronidazole and doxycycline- $\mathrm{HCl}$ on proMMP-3 production in gingival fibroblast. $J$ Korean Acad Periodontol. 2000;30(2):335. doi:10.5051/jkape.2000.30.2.335

92. Buttacavoli M, Albanese NN, Di Cara G, et al. Anticancer activity of biogenerated silver nanoparticles: an integrated proteomic investigation. Oncotarget. 2018;9(11):9685-9705. doi:10.18632/ oncotarget.23859

93. Hajtuch J, Hante N, Tomczyk E, et al. Effects of functionalized silver nanoparticles on aggregation of human blood platelets. Int $J$ Nanomedicine. 2019;14:7399-7417. doi:10.2147/IJN. S213499

94. Youssef MM, El-Mansy MN, El-Borady OM, Hegazy EM. Impact of biosynthesized silver nanoparticles cytotoxicity on dental pulp of albino rats (histological and immunohistochemical study). J Oral Biol Craniofacial Res. 2021;11(3):386-392. doi:10.1016/j.jobcr.2021.04.002

95. Albers CE, Hofstetter W, Siebenrock KA, Landmann R, Klenke FM. In vitro cytotoxicity of silver nanoparticles on osteoblasts and osteoclasts at antibacterial concentrations. Nanotoxicology. 2013;7(1):30-36. doi:10.3109/ 17435390.2011 .626538

96. Halkai K, Mudda J, Shivanna V, Patil V, Rathod V, Halkai R. Cytotoxicity evaluation of fungal-derived silver nanoparticles on human gingival fibroblast cell line: an in vitro study. J Conserv Dent. 2019;22(2):160-163. doi:10.4103/JCD.JCD_518_18

97. Liao C, Li Y, Tjong SC. Bactericidal and cytotoxic properties of silver nanoparticles. Int J Mol Sci. 2019;20(2):449. doi:10.3390/ ijms20020449

98. De Jong WH, Van Der Ven LTM, Sleijffers A, et al. Systemic and immunotoxicity of silver nanoparticles in an intravenous 28 days repeated dose toxicity study in rats. Biomaterials. 2013;34 (33):8333-8343. doi:10.1016/j.biomaterials.2013.06.048

99. Soleimani FF, Saleh T, Shojaosadati SA, Poursalehi R. Green synthesis of different shapes of silver nanostructures and evaluation of their antibacterial and cytotoxic activity. Bionanoscience. 2018;8(1):72-80. doi:10.1007/s12668-017-0423-1

100. Soenen SJ, Manshian B, Montenegro JM, et al. Cytotoxic effects of gold nanoparticles: a multiparametric study. ACS Nano. 2012;6 (7):5767-5783. doi:10.1021/nn301714n

101. Yu M, Huang S, Yu KJ, Clyne AM. Dextran and polymer polyethylene glycol (PEG) coating reduce both 5 and $30 \mathrm{~nm}$ iron oxide nanoparticle cytotoxicity in $2 \mathrm{D}$ and $3 \mathrm{D}$ cell culture. Int $J$ Mol Sci. 2012;13(5):5554-5570. doi:10.3390/ ijms 13055554

102. Sengstock C, Diendorf J, Epple M, Schildhauer TA, Köller M. Effect of silver nanoparticles on human mesenchymal stem cell differentiation. Beilstein J Nanotechnol. 2014;5(1):2058-2069. doi:10.3762/bjnano.5.214

103. Pauksch L, Hartmann S, Rohnke M, et al. Biocompatibility of silver nanoparticles and silver ions in primary human mesenchymal stem cells and osteoblasts. Acta Biomater. 2014;10 (1):439-449. doi:10.1016/j.actbio.2013.09.037

104. Lu W, Senapati D, Wang S, et al. Effect of surface coating on the toxicity of silver nanomaterials on human skin keratinocytes. Chem Phys Lett. 2010;487(1-3):92-96. doi:10.1016/j. cplett.2010.01.027

105. Guo H, Zhang J, Boudreau M, et al. Intravenous administration of silver nanoparticles causes organ toxicity through intracellular ros-related loss of interendothelial junction. Part Fibre Toxicol. 2016;13(1). doi:10.1186/s12989-016-0133-9

106. Mao BH, Tsai JC, Chen CW, Yan SJ, Wang YJ. Mechanisms of silver nanoparticle-induced toxicity and important role of autophagy. Nanotoxicology. 2016;10(8):1021-1040. doi:10.1080/ 17435390.2016.1189614 
107. Weerapreeyakul N, Nonpunya A, Barusrux S, Thitimetharoch T, Sripanidkulchai B. Evaluation of the anticancer potential of six herbs against a hepatoma cell line. Chinese Med (United Kingdom). 2012;7(1):1-7. doi:10.1186/1749-8546-7-15

108. Peña-Morán OA, Villarreal ML, Álvarez-berber L, MenesesAcosta A, Rodríguez-López V. Cytotoxicity, post-treatment recovery, and selectivity analysis of naturally occurring podophyllotoxins from Bursera fagaroides var. fagaroides on breast cancer cell lines. Molecules. 2016;21(8):1013. doi:10.3390/ molecules 21081013

109. Babich H, Wurzburger BJ, Rubin YL, Sinensky MC, Blau L. An in vitro study on the cytotoxicity of chlorhexidine digluconate to human gingival cells. Cell Biol Toxicol. 1995;11(2):79-88. doi:10.1007/BF00767493
110. Hidalgo E, Dominguez C. Mechanisms underlying chlorhexidine-induced cytotoxicity. Toxicol in Vitro. 2001;15(45):271-276. doi:10.1016/S0887-2333(01)00020-0

111. Li YC, Kuan YH, Lee SS, Huang FM, Chang YC. Cytotoxicity and genotoxicity of chlorhexidine on macrophages in vitro. Environ Toxicol. 2014;29(4):452-458. doi:10.1002/tox.21771

112. Ferreira MB, Myiagi S, Nogales CG, Campos MS, LageMarques JL. Time- and concentration-dependent cytotoxicity of antibiotics used in endodontic therapy. J Appl Oral Sci. 2010;18 (3):259-263. doi:10.1590/S1678-77572010000300011

\section{Publish your work in this journal}

The International Journal of Nanomedicine is an international, peerreviewed journal focusing on the application of nanotechnology in diagnostics, therapeutics, and drug delivery systems throughout the biomedical field. This journal is indexed on PubMed Central, MedLine, CAS, SciSearch ${ }^{\mathbb{B}}$, Current Contents ${ }^{\mathbb{B}} /$ Clinical Medicine, $^{2}$
Journal Citation Reports/Science Edition, EMBase, Scopus and the Elsevier Bibliographic databases. The manuscript management system is completely online and includes a very quick and fair peer-review system, which is all easy to use. Visit http://www.dovepress.com/ testimonials.php to read real quotes from published authors. 